\title{
Thermal properties and residual strength after high temperature exposure of cement mortar using ferronickel slag aggregate
}

\author{
Ashish Kumer Saha ${ }^{1 *}$, Prabir Kumar Sarker ${ }^{2}$, Vladimir Golovanevskiy ${ }^{3}$ \\ ${ }^{1} \mathrm{PhD}$ student, School of Civil and Mechanical Engineering, Curtin University, Australia, \\ Email: a.saha@postgrad.curtin.edu.au \\ ${ }^{2}$ Associate Professor, School of Civil and Mechanical Engineering, Curtin University, \\ Australia, Email: p.sarker@curtin.edu.au \\ ${ }^{3}$ Professor, WA School of Mines: Minerals, Energy and Chemical Engineering, Curtin \\ University, Australia, Email: V.Golovanevskiy@curtin.edu.au \\ *Corresponding author
}

\begin{abstract}
This study evaluates the thermal properties of cement mortar using by-product ferronickel slag (FNS) fine aggregate and its residual strength after high temperature exposure. Compressive strength of mortar increased when FNS was used up to 50\% replacement of sand and then reduced with further increase of FNS. Volume of permeable voids (VPV) increased by $4 \%$ and $7 \%$ respectively for using $50 \%$ and $100 \%$ FNS fine aggregate. Thermal conductivity of mortar decreased from $2.34 \mathrm{~W} / \mathrm{m} . \mathrm{K}$ for using $100 \%$ sand to $1.65 \mathrm{~W} / \mathrm{m} . \mathrm{K}$ and $1.16 \mathrm{~W} / \mathrm{m} . \mathrm{K}$ for $50 \%$ and $100 \% \mathrm{FNS}$, respectively. Similarly, specific heat increased from $2.18 \mathrm{MJ} / \mathrm{m}^{3} . \mathrm{K}$ to 2.43 $\mathrm{MJ} / \mathrm{m}^{3}$.K for $100 \%$ replacement of sand by FNS. These changes of VPV and thermal properties are attributed to the cavity of FNS particles, and their larger size and angular shape. Residual strengths of mortar after exposure to $800{ }^{\circ} \mathrm{C}$ were found marginally less for using FNS aggregate. This is attributed to the decrease of thermal conductivity of mortar by FNS. Overall, FNS aggregate showed improved thermal insulating properties and thermal mass of mortar without compromising compressive strength. Therefore, FNS can be considered for use as an energy efficient sustainable building material.
\end{abstract}

Keywords: Ferronickel slag; Heat capacity; Thermal conductivity; Thermal diffusivity; High temperature exposure; Air void; Sustainable building material.

\section{Introduction}

The annual growth of concrete production is estimated as $6 \%$ (Ghods et al, 2017). Demand of concrete is increasing at a high rate due to rapid infrastructure development in many countries like India and China. Production of concrete utilises an enormous amount of natural resources including sand as fine aggregate. Fine aggregate occupies about $25 \%$ to $30 \%$ volume of concrete and it contributes to the density and mechanical properties of concrete. Thus, it is essential to use good quality fine aggregate in concrete production. Natural sand is the most commonly used fine aggregate due to its suitable particle size, inertness, strength and thermal properties. However, good quality sand is not readily available in many countries of the world. As a result, excessive sand mining has occurred in different places that have caused significant damage to the aquatic environment (Preciso et al., 2012; Padmalal et al., 2008). Therefore, use of industrial by-products as replacement of natural sand can help protect the environment by value-added waste utilisation and conservation of natural resources. This study investigated the use of by-product FNS as a replacement of natural sand.

Thermal properties of concrete can play a significant role in sustainable infrastructure development. The stress distribution caused by temperature variation in structural elements can be significantly affected by thermal properties of concrete (Emborg, 2014). Temperature 
variation may induce excessive tensile stress in concrete to cause cracks on surface and throughout cross-section. Mirzazadeh et al. (2016) conducted a study on the response of reinforced concrete at different temperature environments. It was found that low temperature delayed the crack propagation of reinforced concrete at a given load showing a correlation of cracks with temperature differential. Shen et al. (2016) showed that high temperature exposure can lead to an increase in autogenous shrinkage, and the authors developed a model to predict shrinkage of concrete due to different curing temperatures.

Optimisation of thermal insulation of concrete can help reduce the energy required for heating and cooling of buildings and thus reduce the use of fossil fuels (Liu et al. 2014). Mahila et al. (2007) showed that adequate thermal insulation could significantly reduce the operational cost of power plants. Lightweight aggregate and air-entraining agents are often used to improve thermal insulating properties of concrete. Borinaga-Trevino et al. (2013) studied the effects of different fine aggregates such as silica sand, limestone, electric arc furnace (EAF) slag and construction and demolition waste (CDW) on the thermal conductivity of cement mortar. The thermal conductivities of cement mortar using silica sand and EAF slag were found to be 2.1 $\mathrm{W} / \mathrm{mK}$ and $1.5 \mathrm{~W} / \mathrm{mK}$, respectively. According to Kim et al. (2012), use of up to $1.5 \%$ airentraining (AE) agent can significantly improve the thermal insulation of concrete. The experimental study showed that there was $52 \%$ to $55 \%$ reduction of thermal conductivity due to the use of $1.5 \% \mathrm{AE}$ agent that increased porosity. Alengaram et al. (2013) showed that oil palm shell foamed concrete reduced thermal conductivity of concrete by $39 \%$ as compared to control concrete. Ramírez et al. (2013) showed by experimental results that replacement of $80 \%$ natural aggregate by lightweight recycled aggregate provided $65 \%$ reduction in thermal conductivity due to the increase of porosity of concrete. Similarly, use of $30 \%$ hollow glass spheres as coarse aggregate was found to reduce thermal conductivity of concrete by $43 \%$ (Yun et al. 2013). Thus, use of porous aggregate or creation of air voids in concrete improved thermal insulation by reducing thermal conductivity. However, both light-weight aggregates and air voids can result in a significant reduction of strength due to reduced density and increased porosity of concrete (Won et al. 2011).

Thermal conductivity of concrete and mortar also depends on the moisture content because the thermal conductivity of water is twenty-five times higher than that of air (Morabito, 1989). Del Coz Díaz et al. (2013) studied the effects of density and relative humidity on thermal properties of light-weight aggregate concrete. Steiger and Hurd (1978) found that $1 \%$ increase in specific weight of concrete due to water absorption resulted in 5\% increase of its thermal conductivity. Some other factors that are shown to influence thermal conductivity of concrete are volume of cement (Örüng, 1996), aggregate characteristics, mineral admixtures (Fu and Chung, 1997), and temperature (Metha and Monteiro, 2006). Thermal conductivity of concrete is also shown to increase with the increase of density (Institution of Structural Engineers, 1987; Ashworth and Ashworth, 1991; Demirboga and Kan, 2012). Sayadi et al. (2016) proposed an equation to predict thermal conductivity of a very light-weight foamed concrete as a function of the density of concrete and the volume of expanded polystyrene. It is noteworthy that the voids content of concrete have a significant effect on thermal conductivity. A numerical investigation by Del Coz Díaz (2010) showed that the heat transfer through floors made using hollow concrete blocks could be significantly different for different shape and number of the layer of blocks.

Prolonged exposure to elevated temperatures can cause explosive spalling of concrete and lead to structural failures (Won et al. 2011). When exposed to heat, the binder matrix initially loses the physically bound water at about $100{ }^{\circ} \mathrm{C}$ to $150{ }^{\circ} \mathrm{C}$. Decomposition of portlandite and evaporation of chemically bound water occurs between $500{ }^{\circ} \mathrm{C}$ and $550{ }^{\circ} \mathrm{C}$. 
Further increase in temperature leads to the decomposition of calcium carbonate at about 750 ${ }^{\circ} \mathrm{C}$ to $800{ }^{\circ} \mathrm{C}$, and results in a major strength loss (Yüzer et al., 2004; Esteves, 2011; Kodur, 2014). Different techniques have been adopted to improve the resistance of concrete against high temperature exposure. Supplementary cementing materials (SCM) such as ground blast furnace slag (GGBFS), fly ash and metakaolin may show improvement of residual strength up to a temperature of $400{ }^{\circ} \mathrm{C}$ due to the pozzolanic reaction of SCM (Papayianni \& Valliasis, 2005; Li et al., 2012). Use of polyvinyl alcohol (PVA) fibres with low melting point improves fire endurance of concrete by reducing the vapour pressure generated by heat (Soleimanzadeh \& Mydin, 2012).

Since aggregates generally occupy about $70 \%$ to $80 \%$ volume of concrete, thermal properties of aggregate have a significant influence on the thermal properties of concrete. Thermal properties of concrete eventually influence its behaviour when exposed to high temperature heat. According to Topçu \& Işıkdağ (2007), lightweight aggregate exhibited excellent resistance to high temperature exposure due to the reduction of thermal conductivity of concrete. Similarly, Zhang et al. (2000) showed that concretes with lightweight aggregate exhibit remarkable thermal resistance over concrete using normal weight aggregates, while subjected to an elevated temperature of up to $600{ }^{\circ} \mathrm{C}$. According to Kodur \& Sultan (2003), carbonate aggregate exhibited higher fire resistance as compared to siliceous aggregate due to lower thermal conductivity. In addition, Kodur et al. (2003) experimentally showed higher specific heat of carbonate aggregates than siliceous aggregates that prevented spalling of concrete using carbonate aggregate at high temperature. Kong \& Sanjayan (2010) showed that concrete using smaller size aggregates exhibited more cracking than concrete with larger aggregates due to thermal incompatibility between the binder matrix and aggregate. Similarly, Pan et al. (2012) showed that concrete with $10 \mathrm{~mm}$ aggregates suffered from more spalling than concrete with $14 \mathrm{~mm}$ aggregates. This is because larger aggregate creates an elongated fracture process zone to facilitate the escape of vapour pressure. Therefore, the type and size of aggregates showed significant effects on thermal properties of concrete and its response after exposure to high temperature.

The effects of using FNS fine aggregate on thermal properties of cement mortar are presented in this paper. The FNS used in this study is a by-product of the smelting of garnierite nickel ore and was sourced from SLN, New Caledonia. It has been estimated that about 12 tonnes of FNS is generated as by-product in production of 1 tonne ferronickel alloy. Thus, a huge quantity of FNS is available for use as a construction material. A water cooling method was used to granulate the molten slag. As shown in previous studies (Saha \& Sarker, 2016), FNS aggregate consists of high density particles and it can improve compressive strength of concrete when used as a partial replacement of sand. However, full replacement of sand by FNS reduced compressive strength (Saha \& Sarker, 2017b, 2018a). Since thermal properties of a matrix are dependent of the fine aggregate filler, it is essential to evaluate the thermal properties of mortar using FNS aggregate and its effect after the mortar is exposed to high temperature heat. There are no previous studies where thermal properties of cement mortar containing FNS aggregate were evaluated. Therefore, this study was conducted in order to evaluate the thermal properties of mortar using FNS aggregate. Mortar specimens were cast using FNS aggregate as different volume percentage replacements of sand. Various properties such as density, compressive strength, thermal conductivity, thermal diffusivity, specific heat, permeable voids and resistance to elevated temperature of mortar specimens were determined. The effects of FNS aggregate on mortar properties were further investigated by scanning electron microscope (SEM) images of the aggregates and mortars. 


\section{Materials and methods}

\subsection{Materials}

Ordinary Portland cement (OPC) was used as the binder for casting of mortar specimens. The specific surface area and density of OPC were $337 \mathrm{~m}^{2} / \mathrm{kg}$ and $3.15 \mathrm{~g} / \mathrm{cm}^{3}$, respectively. Locally available natural silica sand and ferronickel slag (FNS) were used as fine aggregate. The chemical compositions of OPC and FNS, as determined by X-ray fluorescence (XRF) analysis, are given in Table 1. It can be seen that the main constituents of FNS are silicon, magnesium and iron. Leaching of heavy metals from concrete specimens containing 100\% FNS fine aggregate was studied previously and the results are available in literature (Saha and Sarker, 2017a). It was found that the leaching of heavy metals were much less than the recommended limits of the United States Environmental Protection Agency (US EPA, 2009). Therefore, the use of FNS aggregate in concrete was found environmentally safe in terms of the leaching of heavy metals.

Table 1. Chemical compositions of OPC and FNS (mass percentage).

\begin{tabular}{|c|c|c|}
\hline Chemical composition & OPC & FNS \\
\hline $\mathrm{SiO}_{2}$ & 20.29 & 53.29 \\
\hline $\mathrm{Al}_{2} \mathrm{O}_{3}$ & 5.48 & 2.67 \\
\hline $\mathrm{Fe}_{2} \mathrm{O}_{3}$ & 2.85 & 11.9 \\
\hline $\mathrm{MgO}$ & 1.24 & 31.6 \\
\hline $\mathrm{SO}_{3}$ & 2.49 & - \\
\hline $\mathrm{CaO}$ & 63.11 & 0.42 \\
\hline $\mathrm{Na}_{2} \mathrm{O}$ & 0.29 & 0.11 \\
\hline $\mathrm{K}_{2} \mathrm{O}$ & 0.45 & - \\
\hline $\mathrm{Cr}_{2} \mathrm{O}_{3}$ & 0.02 & 1.08 \\
\hline $\mathrm{P}_{2} \mathrm{O}_{5}$ & 0.17 & - \\
\hline $\mathrm{SrO}$ & 0.05 & - \\
\hline $\mathrm{TiO}_{2}$ & 0.27 & - \\
\hline $\mathrm{Mn}_{2} \mathrm{O}_{3}$ & 0.08 & - \\
\hline $\mathrm{ZnO}$ & 0.04 & - \\
\hline $\mathrm{NiO}$ & - & 0.1 \\
\hline $\mathrm{Co}_{3} \mathrm{O}_{4}$ & - & 0.01 \\
\hline loss on ignition & 3.39 & - \\
\hline
\end{tabular}

The physical properties of aggregates are given in Table 2. It can be seen that FNS has higher specific gravity and fineness modulus as compared to sand. Physical appearances of the aggregates are shown in Fig. 1. FNS aggregate is dark in colour and consists of particles of different sizes. On the other hand, sand consisted of round particles of uniform size. Additionally, presence of some cavities can be visible in the FNS particles, as shown in Fig. 1. Furthermore, the SEM images of FNS and sand particles are shown in Fig. 2. It can be seen that the microstructure of FNS particles is relatively porous as compared to that of natural sand. The large cavity is shown in Fig. 1(a) and the microstructural pores are shown in Fig. 2(a) are 
Materials

\section{Specific gravity Fineness modulus Water absorption (\%)}

\begin{tabular}{llll}
\hline Sand & 2.10 & 1.95 & 0.35 \\
Ferronickel slag (FNS) & 2.78 & 4.02 & 0.42 \\
\hline
\end{tabular}

172

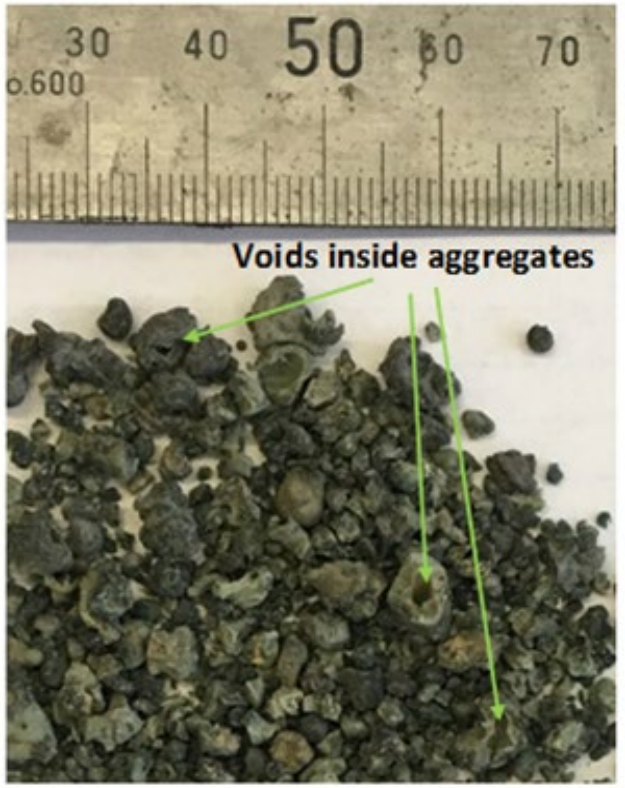

(a) FNS

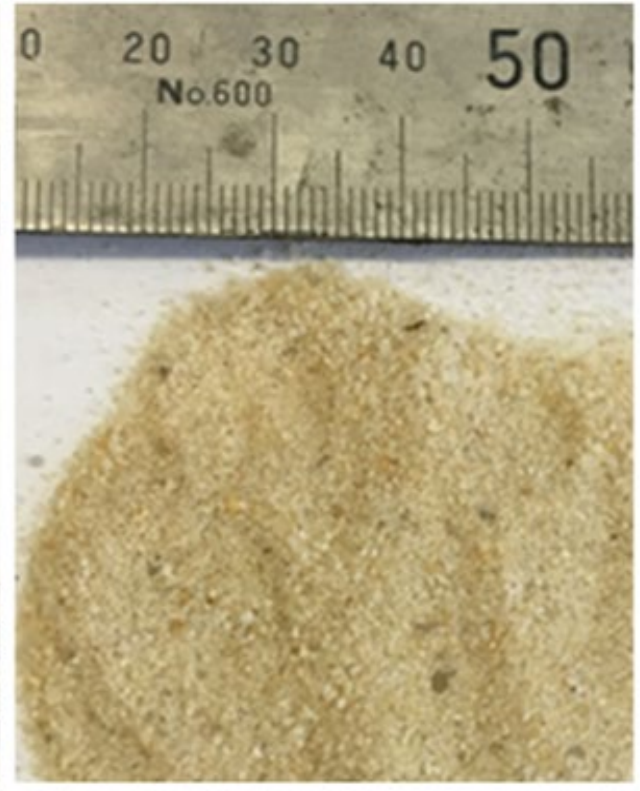

(b) Sand

Fig. 1. Physical appearance of the aggregates. 


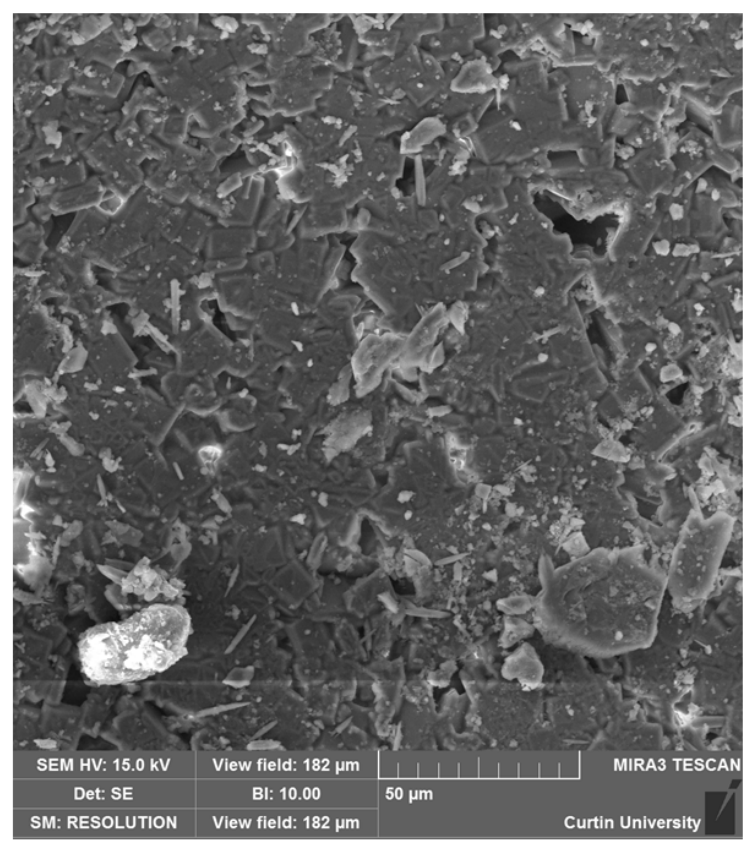

(a) FNS

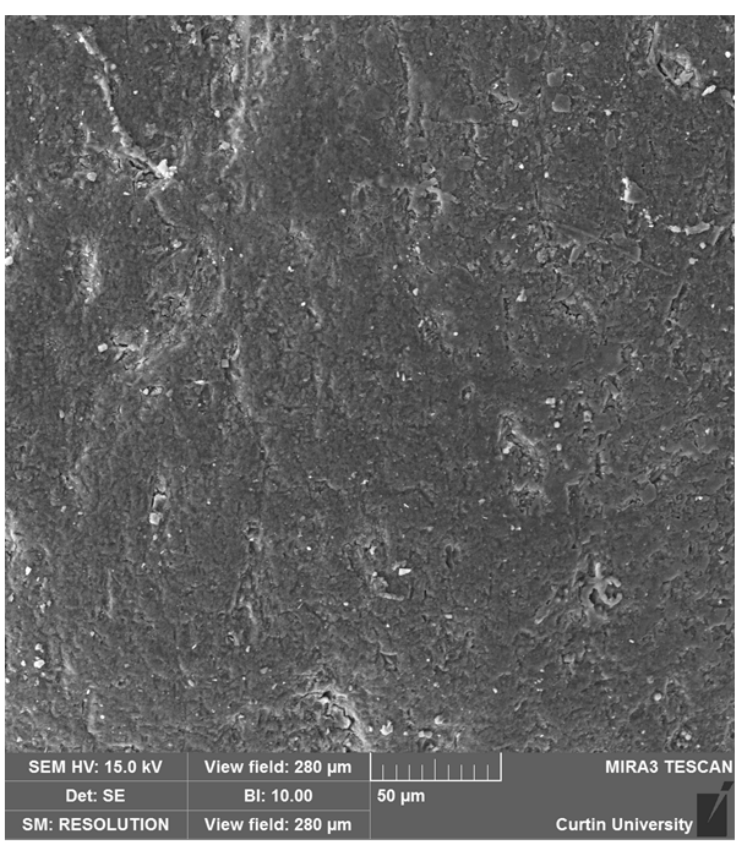

(b) Sand

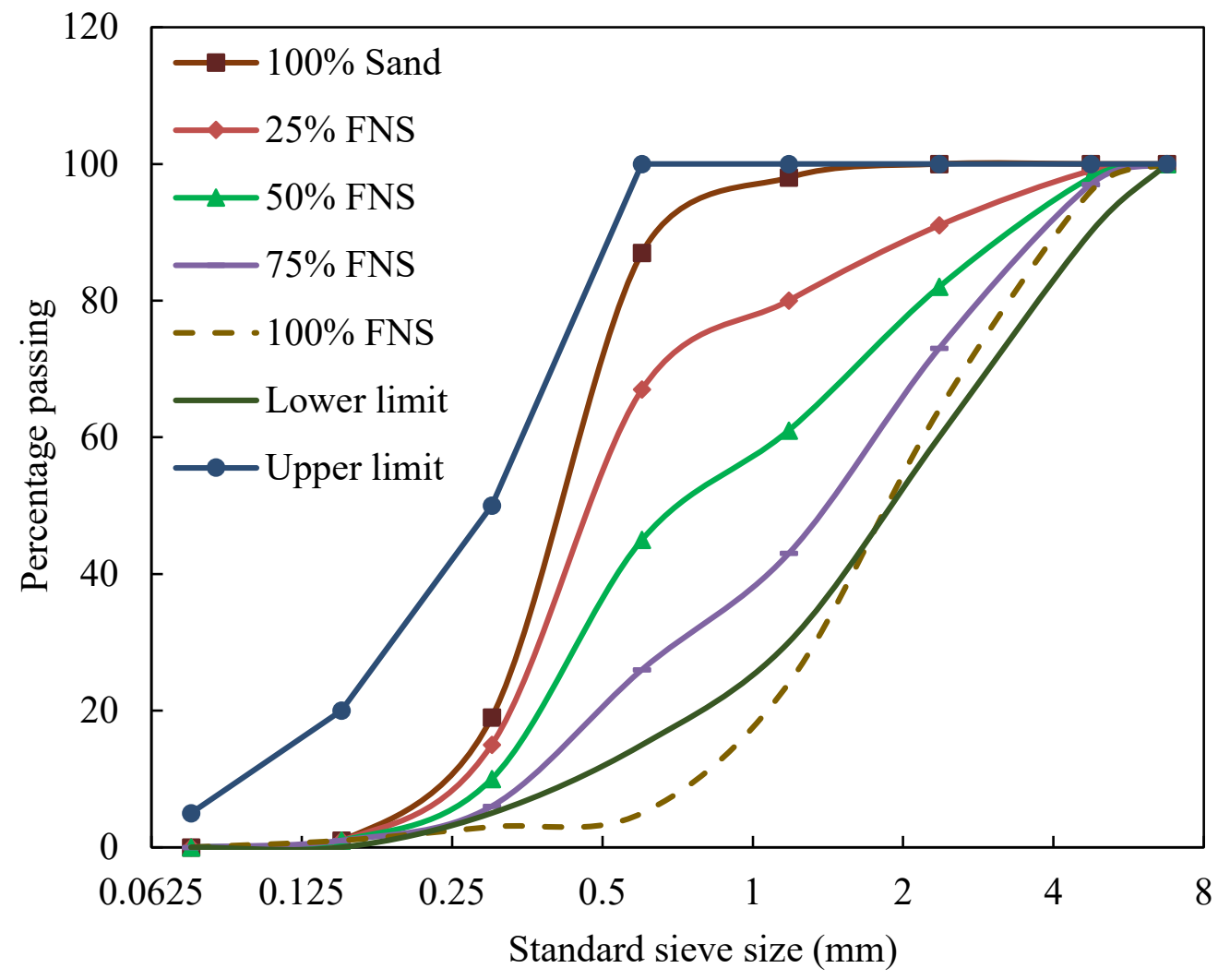

Fig. 2. Microstructures of FNS and sand.

Fig. 3. Grain size distribution of sand, FNS and recommended limits of AS 2758.1 (2014). 


\subsection{Sample preparation and test methods}

The mortar mixtures were mixed according to the guidelines of Australian Standard AS 2701 (2001). Mix proportions are given in Table 3. Cement content of the mixture was $450 \mathrm{~kg} / \mathrm{m}^{3}$ and water to cement ratio was 0.5 . Fine aggregate to binder ratio was 2.75 . Sand was replaced by FNS from $25 \%$ to $100 \%$ volume of the fine aggregate. Five mortar mixtures were studied and the reported results are the average values for three identical specimens. The mixtures are designated by volume percentage of FNS. Fifty-mm cube specimens were cast for compressive strength tests of mortars. The specimens were demoulded at 24 hours after casting and then cured for 28 days. Compressive strength was determined by loading the specimens at a rate of $0.33 \mathrm{MPa} / \mathrm{sec}$. The density and volume of permeable voids (VPV) were determined using mortar cube specimens. VPV was determined from saturated surface dry (SSD) and oven dry masses of the specimens according to ASTM C 642 (2006). SEM images of sand, FNS and the mortar specimens were used to understand the effect of FNS on mortar properties. SEM was conducted by backscatter electron beam with an accelerating voltage of $10 \mathrm{kV}$ and a constant working distance.

Table 3. Mix proportions of mortar.

\begin{tabular}{lccccc}
\hline \multirow{2}{*}{ Sample ID } & OPC $\left(\mathbf{k g} / \mathbf{m}^{\mathbf{3}}\right)$ & \multicolumn{2}{c}{ Fine aggregate $\left(\mathbf{k g} / \mathbf{m}^{\mathbf{3}}\right)$} & Water $\left(\mathbf{k g} / \mathbf{m}^{\mathbf{3}}\right)$ & W/C \\
\cline { 3 - 5 } & & Sand & FNS & & \\
\hline PC-FNS0 & 450 & 1250 & 0 & 275 & 0.50 \\
PC-FNS25 & 450 & 935 & 415 & 275 & 0.50 \\
PC-FNS50 & 450 & 625 & 825 & 275 & 0.50 \\
PC-FNS75 & 450 & 310 & 1240 & 275 & 0.50 \\
PC-FNS100 & 450 & 0 & 1655 & 275 & 0.50 \\
\hline
\end{tabular}

Cylindrical specimens of $100 \mathrm{~mm}$ diameter and $200 \mathrm{~mm}$ height were cast to determine the thermal properties. The cylinders were cut into $30 \mathrm{~mm}$ thick discs after curing in water for 28 days. The specimens were then oven-dried at $105^{\circ} \mathrm{C}$ for 24 hours, cleaned with a soft synthetic-fibre brush and kept in an air-tight container to prevent contamination by airborne dust. Thermal properties analyser Hot Disk TPS 2200 instrument and transient plane source (TPS) technique developed by Gustafsson (1991) was used for the test. Some of the main advantages of using the TPS technique include its inherent ability to measure thermal conductivity and thermal diffusivity in the same measurement step and the small temperature gradients necessary for the measurements (Bouguerra et al., 1997). The latter quality of the TPS method is particularly useful for potentially temperature-affected materials. In our research, all the measurements were conducted at $22 \pm 0.5^{\circ} \mathrm{C}$ temperature and the instrumentinduced temperature gradient was limited to $4.2^{\circ} \mathrm{C}$. Given the $30 \mathrm{~mm}$ thickness of test samples and to ensure no influence of the specimen/specimen holder boundary conditions, the depth of heat flow penetration was limited to $20.0 \mathrm{~mm}$. The experimental setup is shown in Fig. 4 . 


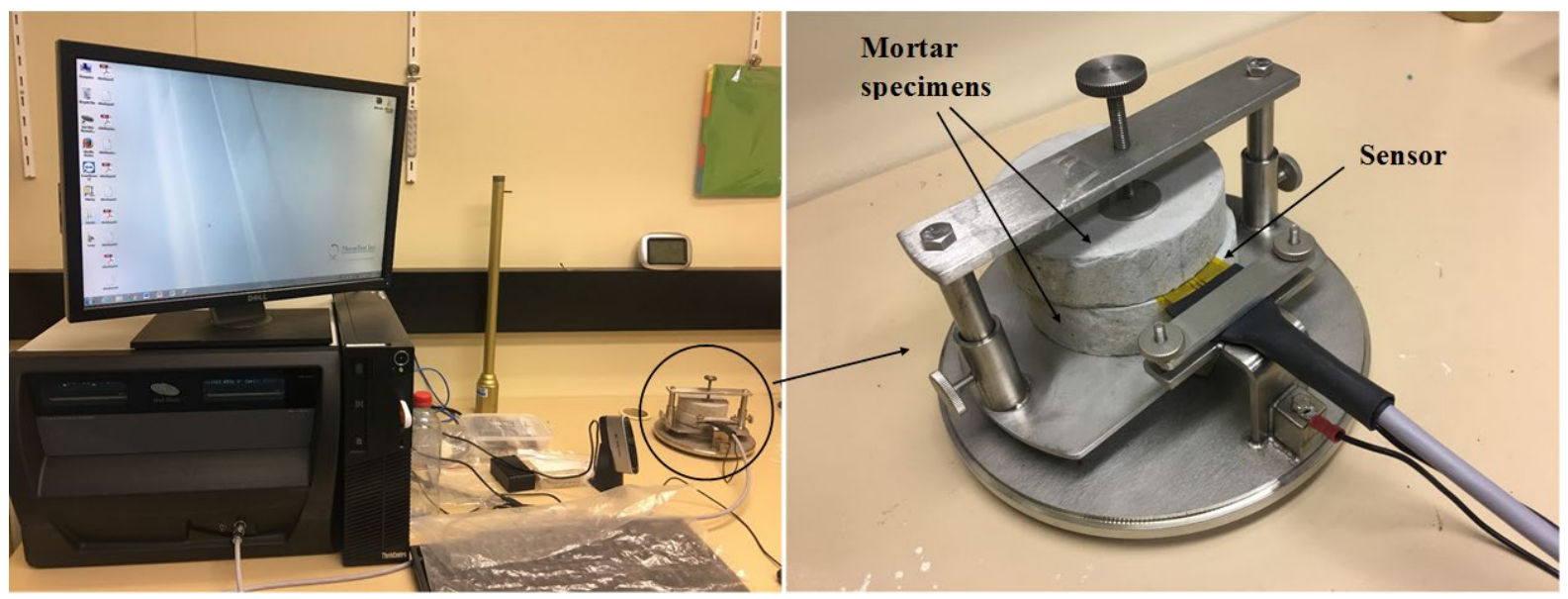

Fig. 4. Experimental set up to determine thermal properties. Note: sample holder cover removed for the photograph.

The test samples were cut in a single cutting step using a rotary masonry saw with a diamond-tipped blade. This ensured that surface of the samples was flat and smooth. Referring to Fig. 4, the sensor of the TPS instrument was positioned in-between the duplicate samples and the assembly was then compressed with the hold-down screw. Good mechanical contact between the TPS sensor and the surfaces of the duplicate specimens ensured good thermal contact and this minimized any potential influence of surface resistance on the results. This approach to minimise thermal contact resistance has been a widely accepted practice (Berman, 1956; Thomas and Probert, 1970; Williamson and Majumdar, 1992). Additionally, Gustaffson et al. (1986) found that the influence of thermal contact resistances in the transient thermal measurements appeared only for a short time period at the beginning of the measurement, where it presented as a constant temperature difference which could be easily recognised by the thermal analysis software. In our research, the constant temperature difference due to thermal contact resistance at the beginning of all measurements was of the order of $0.1 \mathrm{mK}$ and appeared for less than $5 \mathrm{~ms}$ only (at the total measurement time of $80 \mathrm{~s}$ ). It was recognised and separated from the transient temperature increase in the bulk material by thermal analysis software.

The residual strengths after exposure to elevated temperature were evaluated by heating the $50 \mathrm{~mm}$ cube specimens in an electric furnace. The samples were heated to $200{ }^{\circ} \mathrm{C}, 400{ }^{\circ} \mathrm{C}$, $600{ }^{\circ} \mathrm{C}$ and $800{ }^{\circ} \mathrm{C}$ with a temperature increment rate of $5{ }^{\circ} \mathrm{C}$ per minute. After reaching the designated temperature level, the temperature was kept constant for two hours. The samples were then cooled down to room temperature naturally by opening the door of the furnace. The mass and compressive strength were determined after cooling down the specimens to room temperature.

\section{Results and discussion}

\subsection{Density of hardened mortar}

The average densities of the hardened mortars in saturated surface dry (SSD) condition and oven-dry condition are presented in Table 4. It can be seen that the SSD density varied in a range of $1945 \mathrm{~kg} / \mathrm{m}^{3}$ to $2361 \mathrm{~kg} / \mathrm{m}^{3}$. 
Table 4. Density of hardened mortar.

\begin{tabular}{lcc}
\hline Mix ID & SSD density $\left(\mathbf{k g} / \mathbf{m}^{\mathbf{3}}\right)$ & Oven-dry density $\left(\mathbf{k g} / \mathbf{m}^{\mathbf{3}}\right)$ \\
\hline PC-FNS0 & 1945 & 1735 \\
PC-FNS25 & 2060 & 1834 \\
PC-FNS50 & 2143 & 1897 \\
PC-FNS75 & 2258 & 1961 \\
PC-FNS100 & 2361 & 2023 \\
\hline
\end{tabular}

As shown in Fig. 5, density of the mortar increased linearly with the increase of FNS content. This is due to the higher particle density of FNS aggregate than sand. It can also be seen that the densities of the oven-dry samples were $11 \%-15 \%$ less than the SSD samples. The differences between the oven-dry and SSD densities of mortars PC-FNS0, PC-FNS25, PCFNS50, PC-FNS 100 and PC-FNS100 were $210 \mathrm{~kg} / \mathrm{m}^{3} 226 \mathrm{~kg} / \mathrm{m}^{3}, 248 \mathrm{~kg} / \mathrm{m}^{3}, 297 \mathrm{~kg} / \mathrm{m}^{3}$ and $338 \mathrm{~kg} / \mathrm{m}^{3}$, respectively. Therefore, moisture content of mortar specimens gradually increased with the increase of FNS aggregate. While air-dry samples were used for the compressive strength tests, the samples used for thermal conductivity tests were in oven-dry condition in order to avoid the interference of the water content (Sengul et al. 2011).

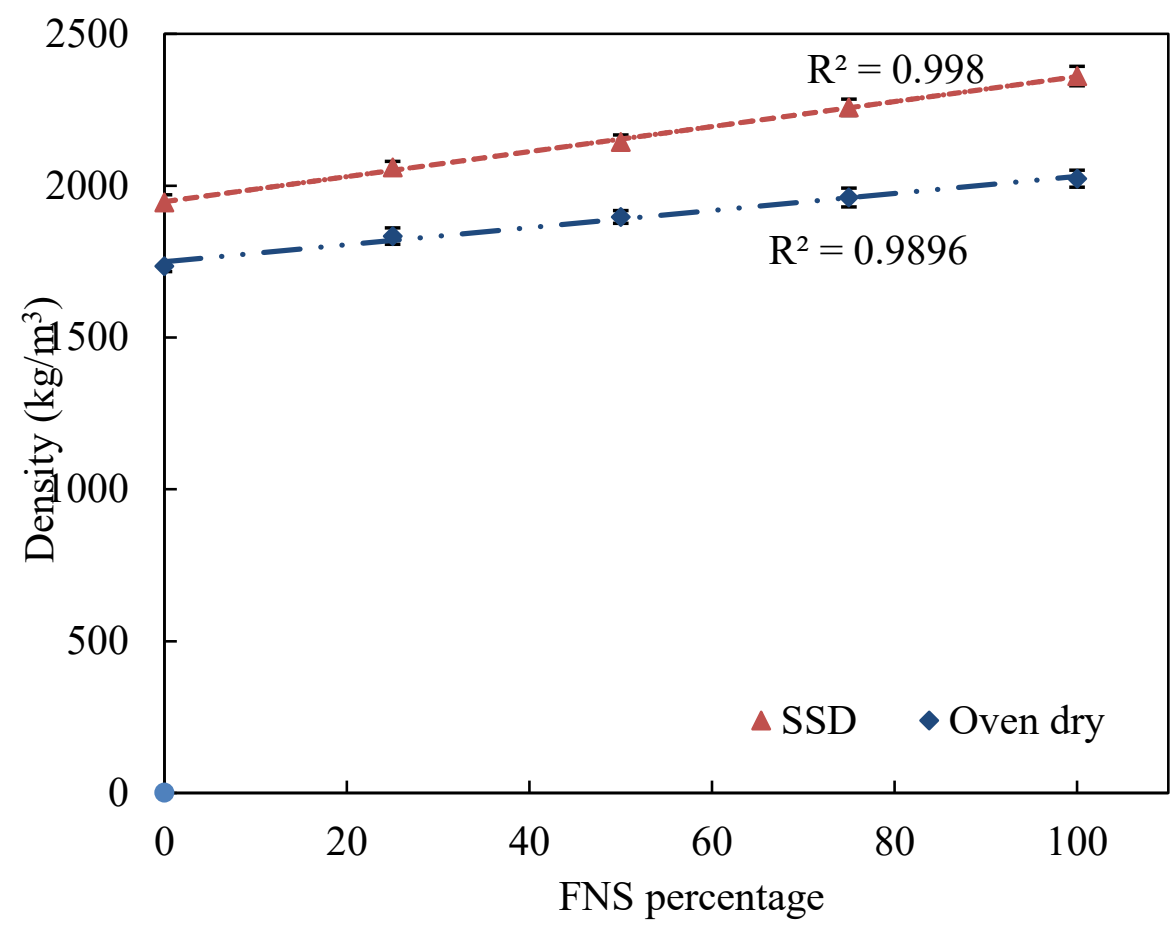

Fig. 5. Relationship between density and the FNS content. 


\subsection{Compressive strength}

The compressive strength results are shown in Fig. 6. As expected, compressive strength mortar increased significantly between 7 days and 28 days, while it became almost steady between 28 days and 56 days of age. This trend was consistent for all the five mortar mixtures. As in conventional mortar using natural sand, majority of the compressive strength development of mortars using FNS aggregate occurred during the first 7 days of curing. It can be seen that the 7-day compressive strengths of mortars PC-FNS0, PC-FNS25, PC-FNS50, PC-FNS75 and PCFNS100 were $73 \%, 78 \%, 74 \%, 70 \%$ and $66 \%$ of their 56 -day strengths, respectively. Furthermore, the 28-day strengths of mortars PC-FNS0, PC-FNS25, PC-FNS50, PC-FNS75 and PC-FNS100 were $96 \%, 97 \%, 96 \%, 96 \%$ and $97 \%$ of their 56-day strength, respectively. Thus, the strength development after the age of 28 days was relatively low.

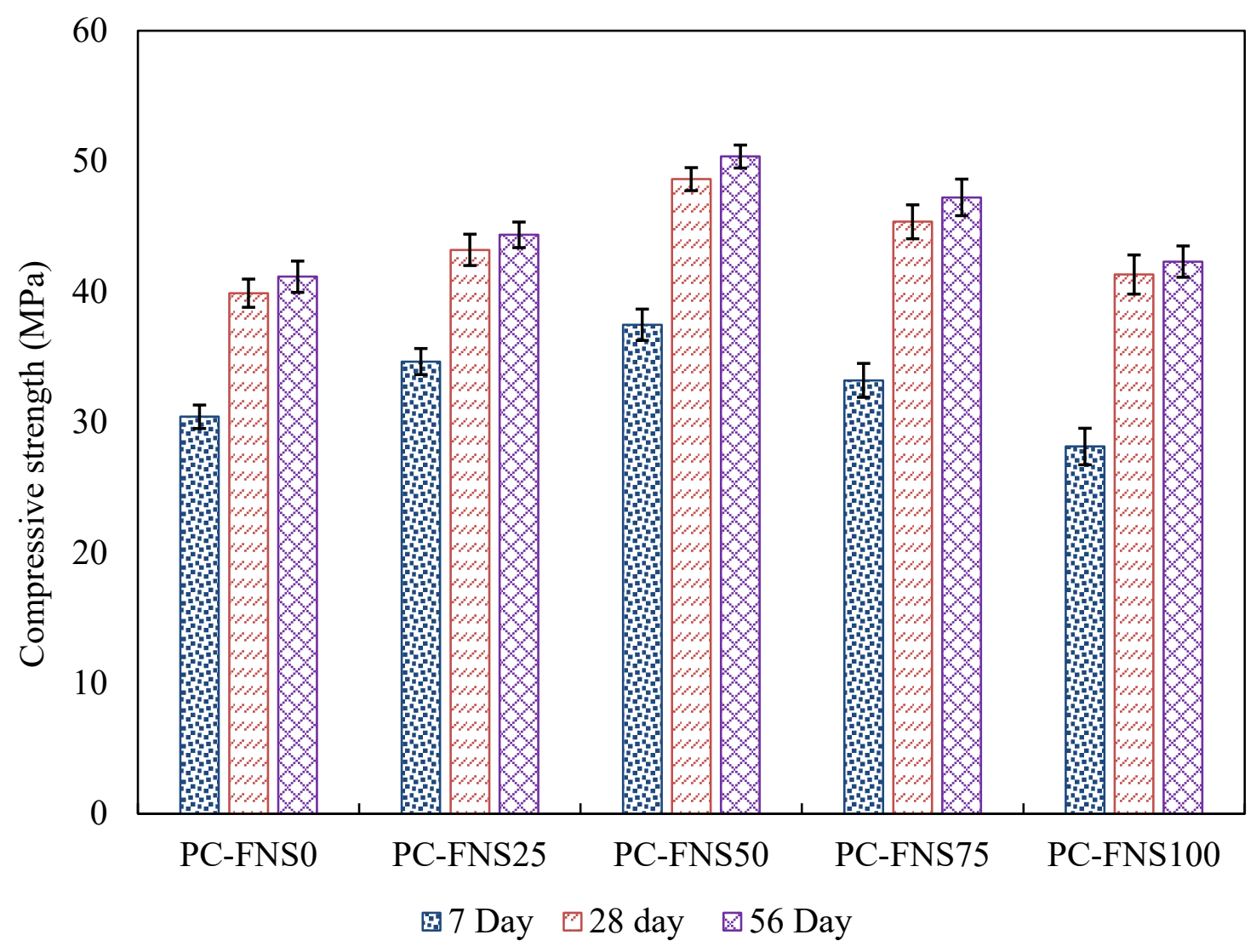

Fig. 6. Compressive strength of the mortar samples.

It can also be seen that compressive strength at any particular age improved with the increment of FNS up to 50\% replacement of sand. However, further increase of FNS content resulted in decline of compressive strength. The 28-day mortar compressive strengths were 40 $\mathrm{MPa}, 43 \mathrm{MPa}, 48 \mathrm{MPa}, 45 \mathrm{MPa}$ and $41 \mathrm{MPa}$ for using $0 \%, 25 \%, 50 \%, 75 \%$ and $100 \% \mathrm{FNS}$ aggregate, respectively. Therefore, the strength increments were $8 \%, 21 \%, 13 \%$ and $3 \%$ for using $25 \%, 50 \%, 75 \%$, and $100 \%$ FNS, respectively. It is usual for concrete and mortar to show higher compressive strength for higher density due to better particle packing and lower voids content (Güneyisi et al. 2016; Bogas et al. 2015). Thus, the increase of mortar strength by using FNS aggregate is attributed to the increase of the density of specimens. As shown in Fig. 3, the combination of $50 \%$ sand with $50 \%$ FNS resulted in a well-graded aggregate. However, the FNS contents above $50 \%$ increased the voids content due to their angular shape and larger size. 
This caused a decline in the compressive strength of mortar using FNS contents of $75 \%$ and $100 \%$. Similar effect of FNS fine aggregate content was also observed on the compressive strength of concrete specimens (Saha \& Sarker 2017a, 2018b).

\subsection{Volume of permeable voids}

In order to evaluate the porosity of the samples, the volume of permeable voids (VPV) was determined. The test measures the ease with which water can penetrate into a mortar or concrete sample. The combination of air voids, capillary pores, gel pores and micro-cracks is determined by the VPV (Andrews-Phaedonos, 2008).

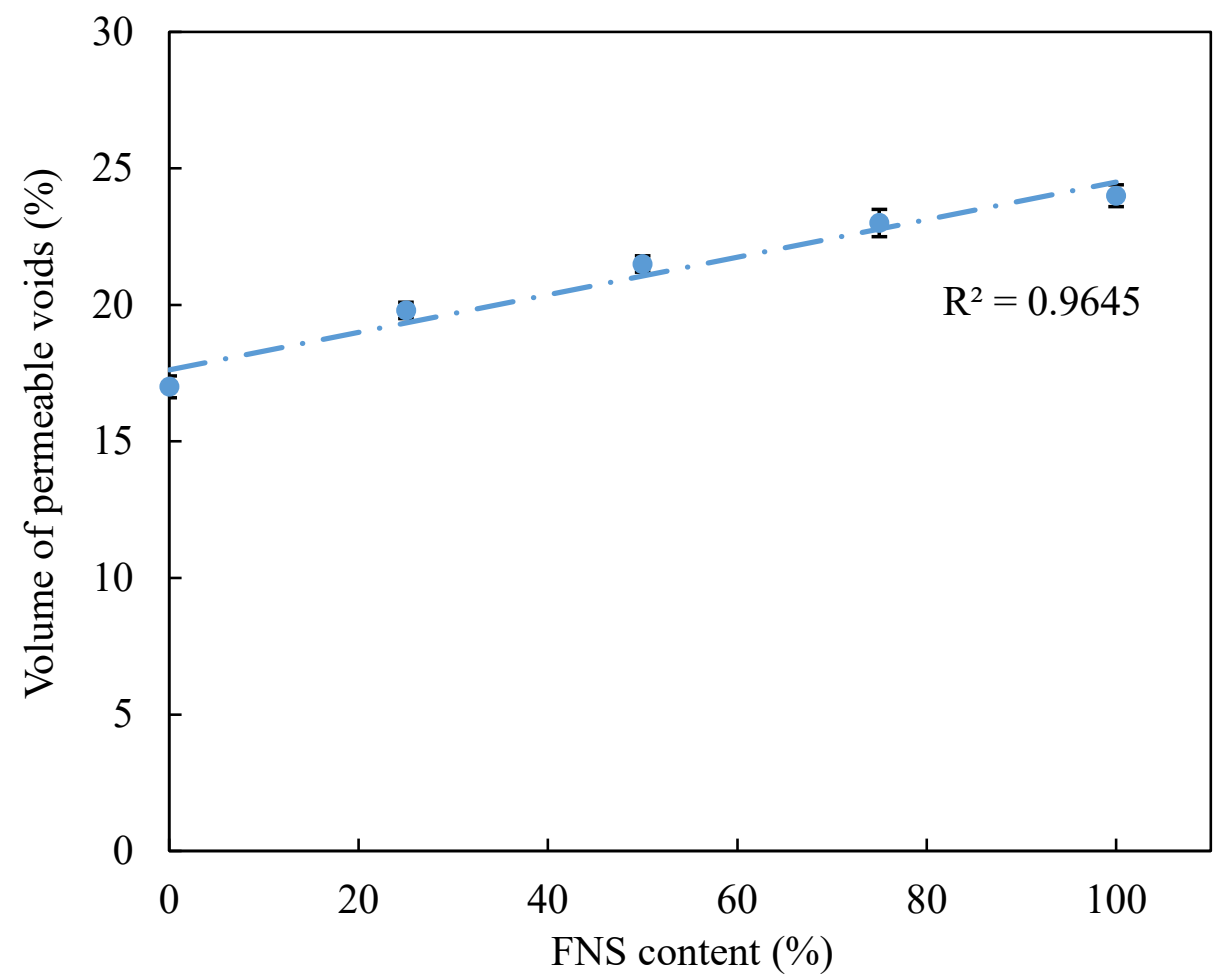

Fig. 7. Relationship between VPV and FNS aggregate content.

The experimental results of VPV are shown in Fig. 7. It can be seen that VPV of mortar increased with the increase of FNS content. VPV of the specimens PC-FNS0, PC-FNS25, PCFNS50, PC-FNS 75 and PC-FNS100 were $17 \%, 20 \%, 21 \%, 23 \%$, and $24 \%$, respectively. The increase of VPV indicates an increase of the porosity of mortar with the increase of FNS content. For instance, VPV of mortar increased by $4 \%$ and $7 \%$ for using $50 \%$ and $100 \%$ FNS aggregate, respectively, as compared to using $100 \%$ sand. 


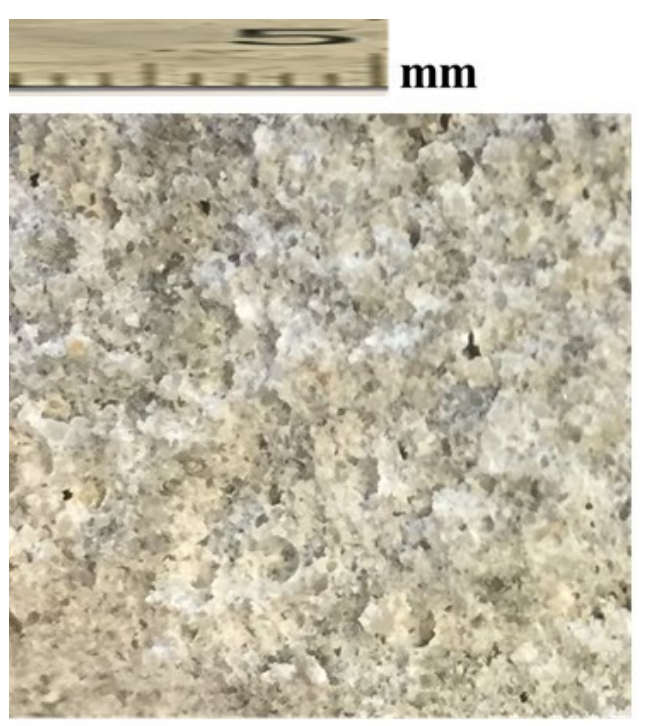

(a) PC-FNS0

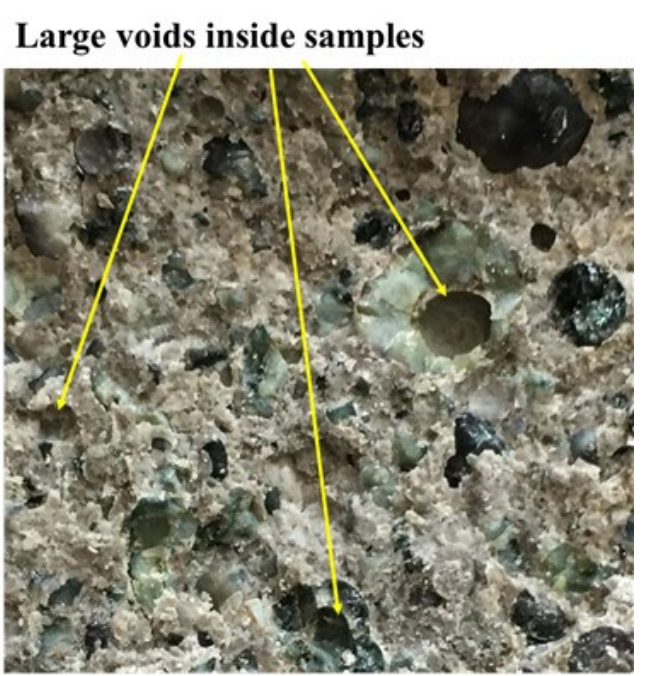

(b) PC-FNS100

Fig. 8. Imges of mortar cross section after 28 days of curing $(10 \times$ magnification $)$.

Magnified views of the cross-section of mortar specimens and SEM images of the microstructure were investigated in order to further understand the increase of porosity by FNS. It can be seen from the magnified view of the cross-section in Fig. 8 that there were relatively large air voids in the cross-section of specimen PC-FNS100 as compared to that of PC-FNS0. These air voids are produced by the cavities of FNS particles, as shown in Fig. 1(a). The SEM images of Fig. 9 shows that the microstructures of the binder matrix were very similar in the specimens of PC-FNS100 and PC-FNS0. Therefore, the increase of VPV or porosity in the specimens using FNS aggregate is contributed mostly by the cavities and micropores of the FNS particles shown in Fig. 1(a) and 2(a), respectively. Overall, the increase of porosity is attributed to the presence of voids in FNS particles and the relatively large size and angular shape of the particles.

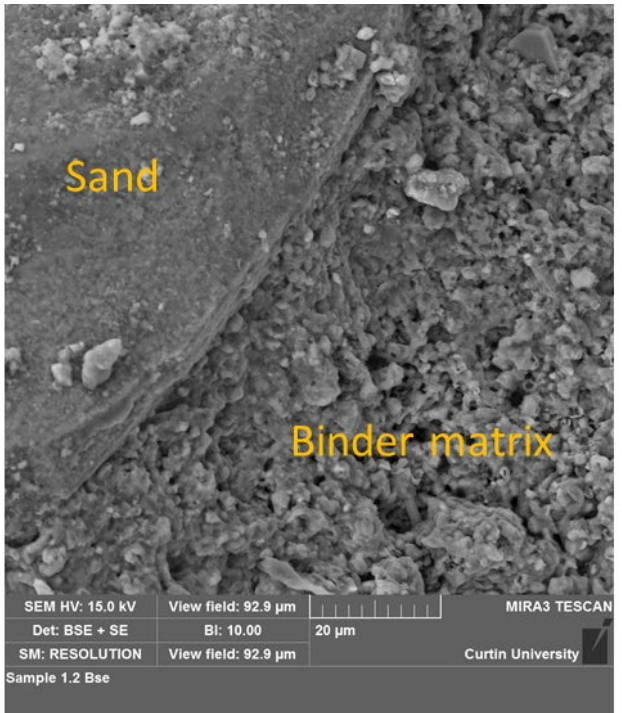

(a) PC-FNS0

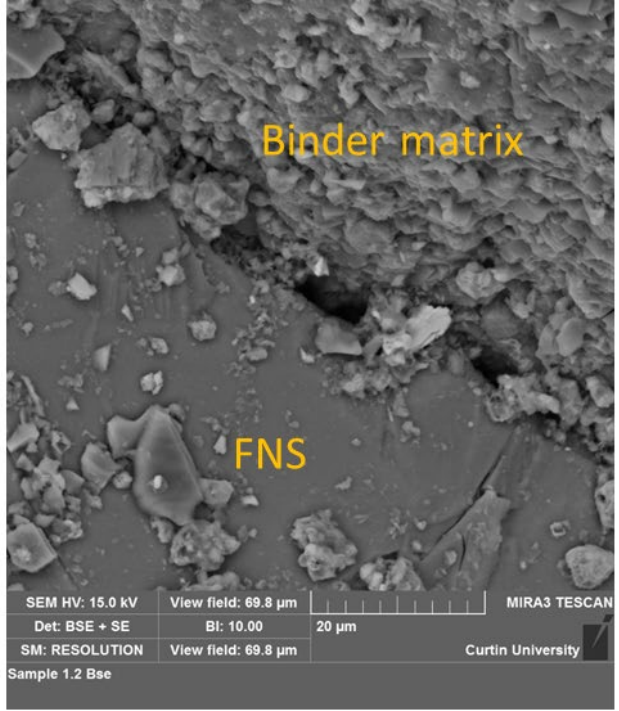

(b) PC-FNS100

Fig. 9. SEM images of mortar cross section after 28 days of curing. 


\subsection{Thermal properties}

The thermal properties of hardened mortar specimens are given in Table 5. The thermal conductivity values of mortars PC-FNS0, PC-FNS25, PC-FNS50, PC-FNS75 and PC-FNS100 were $2.34 \mathrm{~W} / \mathrm{m} \cdot \mathrm{K}, 1.58 \mathrm{~W} / \mathrm{m} \cdot \mathrm{K}, 1.65 \mathrm{~W} / \mathrm{m} \cdot \mathrm{K}, 1.36 \mathrm{~W} / \mathrm{m} \cdot \mathrm{K}$ and $1.16 \mathrm{~W} / \mathrm{m} \cdot \mathrm{K}$, respectively. The results show that thermal conductivity exhibited a decreasing trend with the increase of FNS content despite the higher specific gravity of FNS than sand. It can be noted from Table 2 that the specific gravities of FNS and sand were 2.78 and 2.10, respectively. A decrease of thermal conductivity by the use of high-density EAF slag was also reported by BorinagaTrevino et al. (2013). The specific gravities of sand and EAF slag were 2.65 and 3.82, and the corresponding thermal conductivities of cement mortars were $2.1 \mathrm{~W} / \mathrm{m} \cdot \mathrm{K}$ and $1.5 \mathrm{~W} / \mathrm{m} \cdot \mathrm{K}$, respectively. The decreasing trend of thermal conductivity with the increase of FNS is attributed to the increase of VPV, as shown in Fig. 7. The large cavities (Fig. 8) and micropores (Fig. 2) of FNS particles increased the porosity of mortar. This increase of air voids inhibited the heat flow that reduced the thermal conductivity of the specimens. The effect of the voids in FNS particles on thermal conductivity was found to be significant since $60 \%$ volume of the mortar is occupied by aggregate.

Table 5. Thermal properties of mortar samples.

\begin{tabular}{lccc}
\hline Mix ID & $\begin{array}{c}\text { Thermal } \\
\text { conductivity, } \\
\mathbf{W} / \mathbf{m} \cdot \mathbf{K}\end{array}$ & $\begin{array}{c}\text { Thermal } \\
\text { diffusivity, } \\
\mathbf{m m}^{2} / \mathbf{s}\end{array}$ & $\begin{array}{c}\text { Specific heat, } \\
\mathbf{M J} / \mathbf{m}^{\mathbf{3}} \cdot \mathbf{K}\end{array}$ \\
\hline PC-FNS0 & 2.34 & 1.07 & 2.18 \\
PC-FNS25 & 1.58 & 0.79 & 2.00 \\
PC-FNS50 & 1.65 & 0.74 & 2.24 \\
PC-FNS75 & 1.36 & 0.61 & 2.26 \\
PC-FNS100 & 1.16 & 0.48 & 2.43 \\
\hline
\end{tabular}

In addition to thermal conductivity, thermal diffusivity and heat capacity are two other important parameters defining the heat transfer properties of a material. Thermal diffusivity represents the rate of heat transfer through the material and heat capacity or specific heat is the ratio of thermal energy absorbed or lost by a material to the corresponding temperature change (Lightfoot et al., 1960; Resnick and Halliday, 1966). As given in Table 5, thermal diffusivity values of the mortars PC-FNS0, PC-FNS25, PC-FNS50, PC-FNS75 and PC-FNS100 were 1.07 $\mathrm{mm}^{2} / \mathrm{s}, 0.79 \mathrm{~mm}^{2} / \mathrm{s}, 0.74 \mathrm{~mm}^{2} / \mathrm{s}, 0.61 \mathrm{~mm}^{2} / \mathrm{s}$ and $0.48 \mathrm{~mm}^{2} / \mathrm{s}$, respectively. 


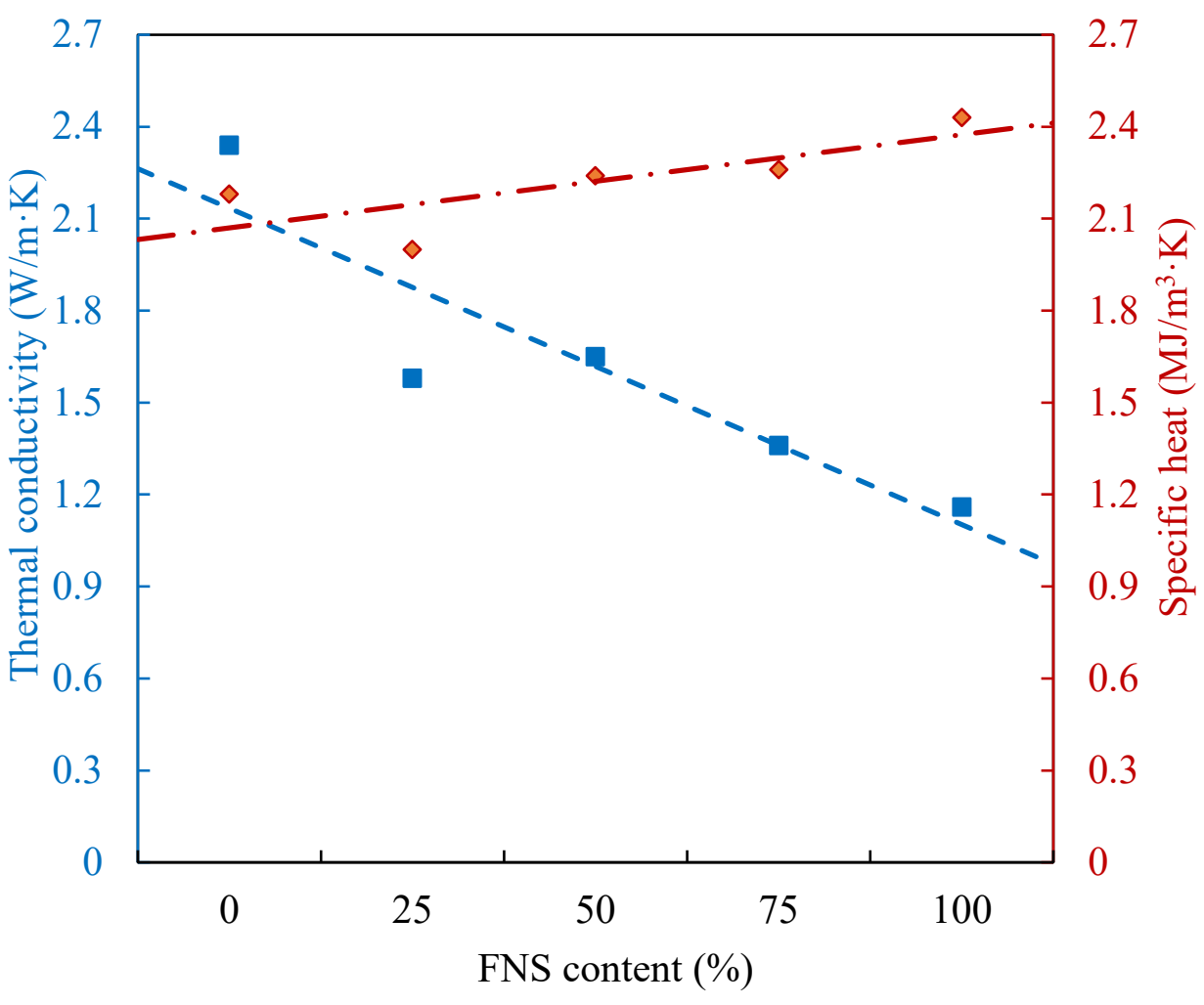

Fig. 10. Variation of thermal conductivity and specific heat with FNS content.

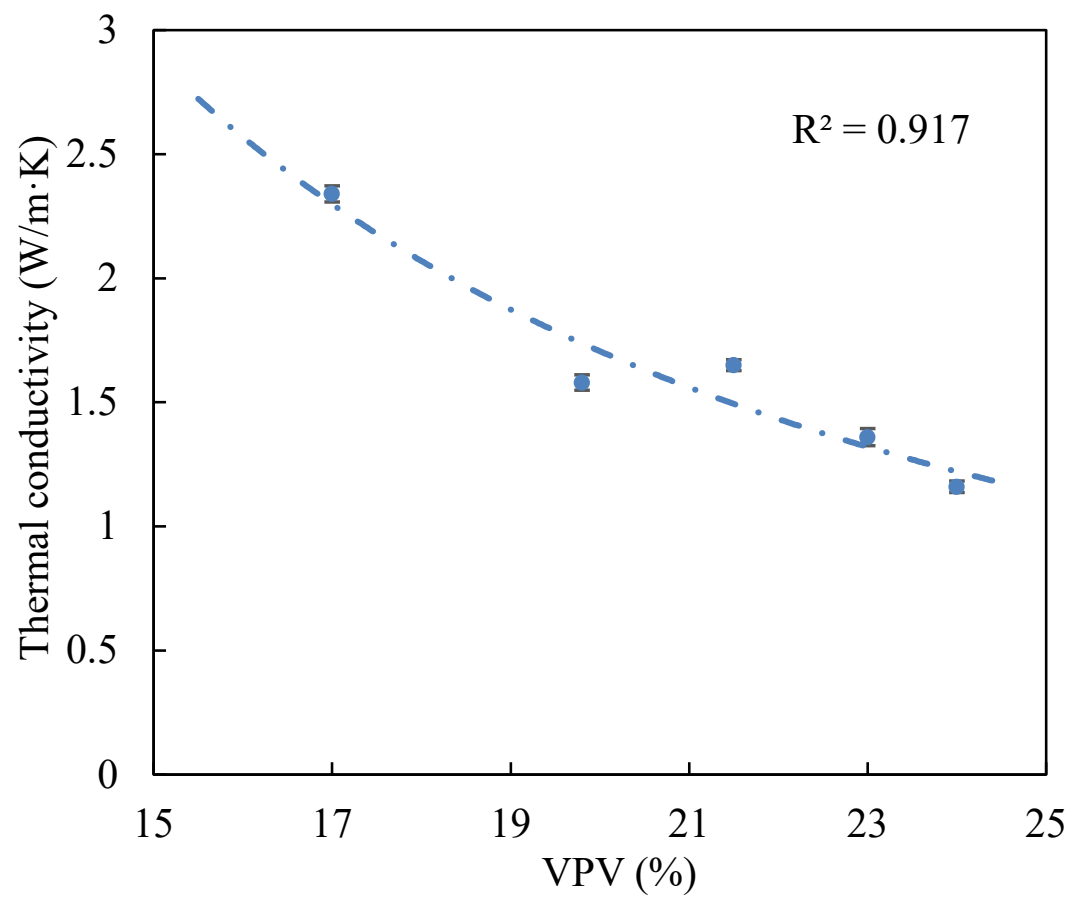

Fig. 11. Variation of thermal conductivity with VPV. 
The variation of thermal conductivity and specific heat with FNS content are shown in Fig. 10. It can be seen that there was a gradual decrease in thermal diffusivity with the increase of FNS aggregate due to the increment of internal pores inhibiting the heat flow. The increase in porosity of the samples has also been reflected in the corresponding increase in their heat capacity values. Specific heat is the amount of heat required to increase temperature of a sample to a unit value and there was a gradual increment of air voids with the increase of FNS content in mortar samples, as shown in Fig. 7. As a result, a higher amount of heat transfer was required for the FNS mortar samples to raise the temperature. This is the reason for a proportional relationship between specific heat and FNS content as shown in Fig. 10.

Furthermore, in order to evaluate the relationship between the thermal conductivity and porosity of the samples, the thermal conductivity values are plotted against the VPV, as shown in Fig. 11. It can be seen that thermal conductivity gradually decreased with the increase of VPV. A Power regression analysis between these two parameters shows a good correlation with a degree of determination $\left(\mathrm{R}^{2}\right)$ value of 0.92 . This confirms the hypothesis that the presence of air voids was the primary reason behind low thermal conductivity of mortars containing FNS aggregates despite their higher density as compared to the control samples.

\subsection{Residual properties of mortar after exposure to elevated temperature}

\section{$\underline{\text { 3.5.1 Visual observation }}$}

The mortar specimens were visually inspected before and after the exposure to elevated temperature. The samples were exposed to four different peak temperatures from $200{ }^{\circ} \mathrm{C}$ to $800{ }^{\circ} \mathrm{C}$. The typical photographs of mortar specimens PC-FNS0, PC-FNS50 and PC-FNS100 taken after cooling down to room temperature from different temperature exposures are presented in Fig. 12, Fig. 13 and Fig. 14, respectively.

It can be seen from Fig. 12 (a) that an exposure to $200{ }^{\circ} \mathrm{C}$ did not cause any noticeable damage to the control specimen. Referring to Fig. 13 (a) and Fig. 14 (a), the PC-FNS50 and PC-FNS100 samples were also free of any visual damage. Similarly, there was no crack in the specimens containing $25 \%$ and $75 \%$ FNS aggregate exposed to $200{ }^{\circ} \mathrm{C}$. After exposure to 400 ${ }^{\circ} \mathrm{C}$, some fine cracks were noticeable on the surface of the PC-FNS0 samples, as shown in Fig. 12 (b). Similar thin cracks were consistently seen in all the five types of mortar specimens. For instance, the cracks of the specimens using 50\% FNS and 100\% FNS aggregate are shown in Fig. 13 (b) and Fig. 14 (b), respectively. 


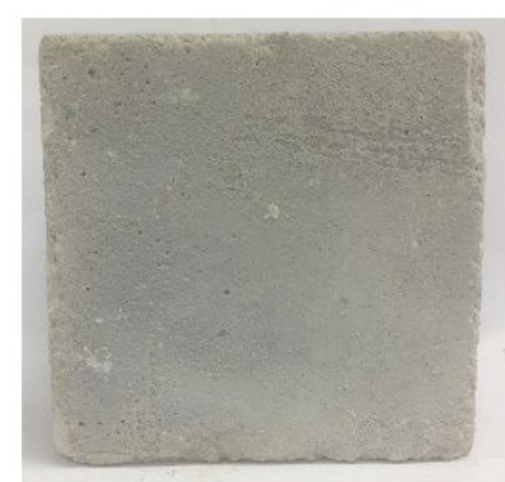

(a) After $200^{\circ} \mathrm{C}$ exposure

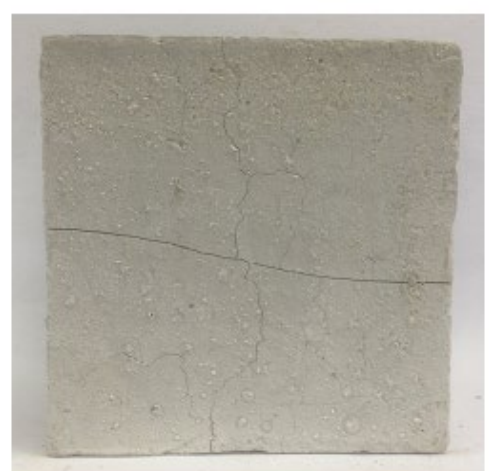

(c) After $600^{\circ} \mathrm{C}$ exposure

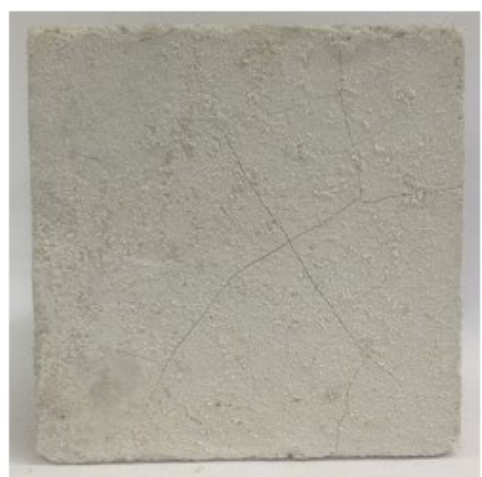

(b) After $400{ }^{\circ} \mathrm{C}$ exposure

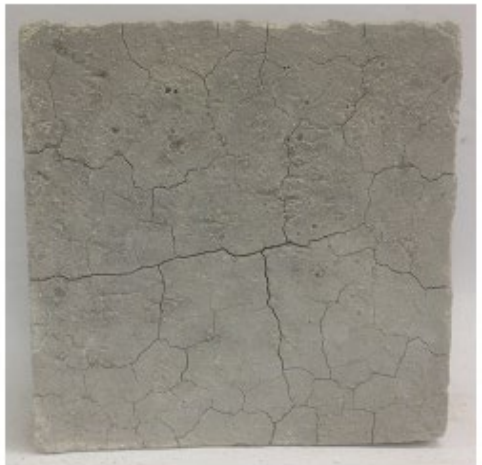

(d) After $800{ }^{\circ} \mathrm{C}$ exposure

Fig. 12. Appearance of PC-FNS0 specimens after elevated temperature exposure.

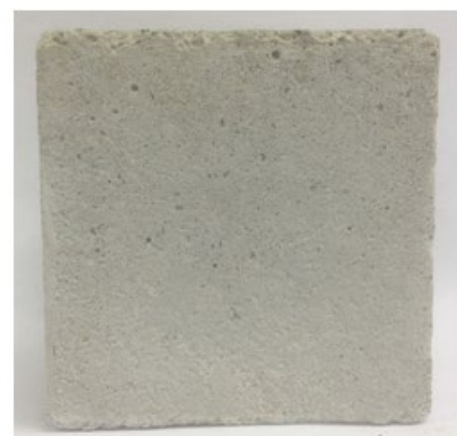

(a) After $200{ }^{\circ} \mathrm{C}$ exposure

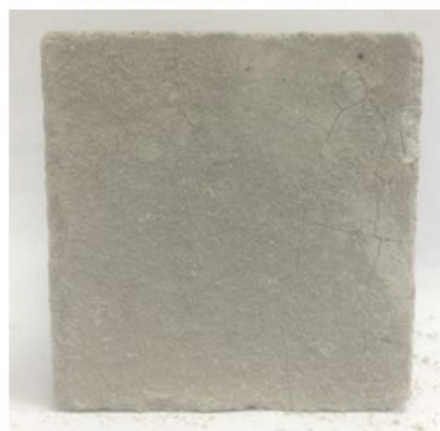

(c) After $600^{\circ} \mathrm{C}$ exposure

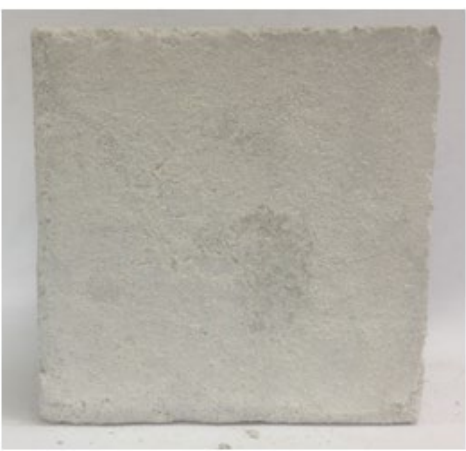

(b) After $400^{\circ} \mathrm{C}$ exposure

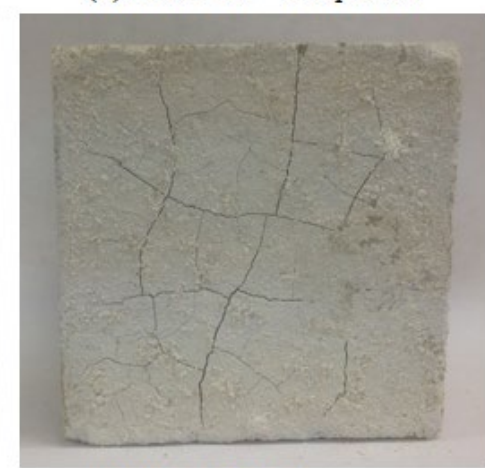

(d) After $800^{\circ} \mathrm{C}$ exposure

Fig. 13. Appearance of PC-FNS50 samples after elevated temperature exposure. 


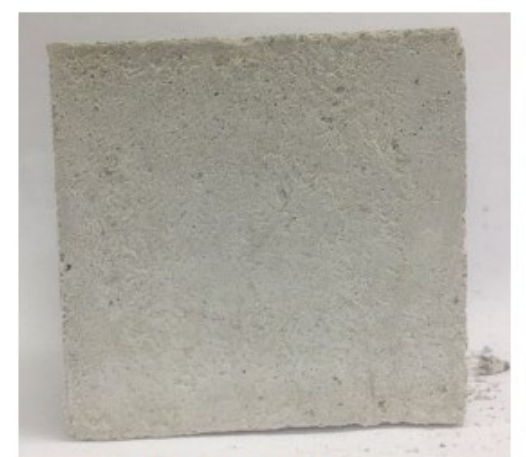

(a) After $200^{\circ} \mathrm{C}$ exposure

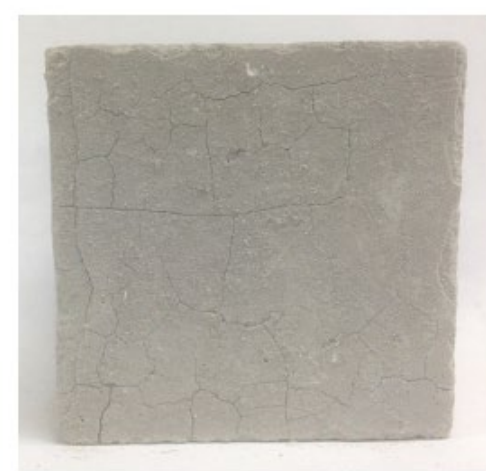

(c) After $600^{\circ} \mathrm{C}$ exposure

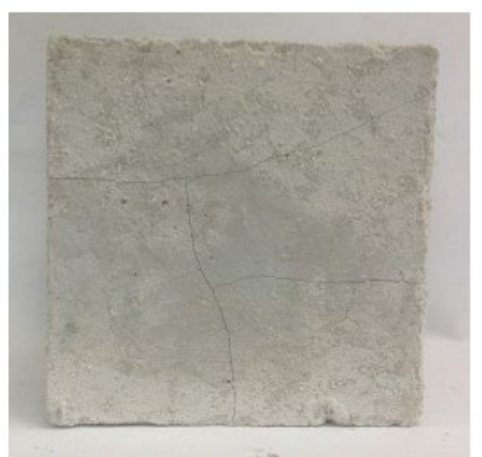

(b) After $400{ }^{\circ} \mathrm{C}$ exposure

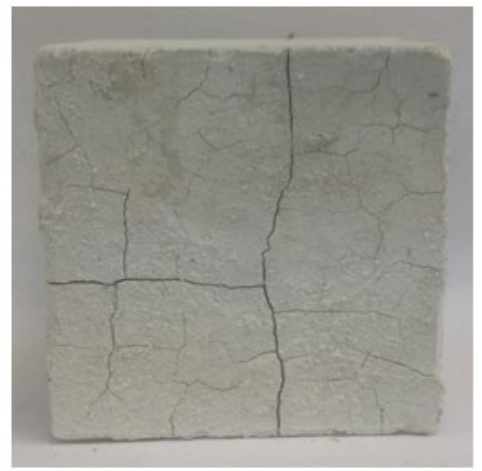

(d) After $800{ }^{\circ} \mathrm{C}$ exposure

Fig. 14. Appearance of PC-FNS100 samples after elevated temperature exposure.

After $600{ }^{\circ} \mathrm{C}$ exposure, the cracks on the surface of specimens PC-FNS0, PC-FNS50 and PC-FNS100 can be seen in Fig. 12 (c), Fig. 13 (c) and Fig. 14 (c), respectively. It can be seen that the number of cracks increased in all three cases as compared to Figs. 12 (b), 13 (b) and 14 (b). Nevertheless, at this temperature, similar types of cracks were seen on surface of the specimens using different volumes of FNS aggregate. Finally, after the exposure to $800{ }^{\circ} \mathrm{C}$, all mortar specimens exhibited significantly increased number of cracks on the surface as shown in Figs. 12 (d), 13 (d) and 14 (d). No spalling was observed in the specimens at this very high-temperature exposure of $800{ }^{\circ} \mathrm{C}$ for two hours. It was shown previously that mortar and concrete with high-density aggregates could experience explosive spalling at high-temperature exposure due to high vapour pressure (Ma et al., 2015). However, no such spalling was not observed in the mortar specimens containing up to $100 \%$ FNS aggregate. This is considered to be due to the higher porosity of the specimens using FNS aggregate that eased the release of internal vapour pressure. For this reason, excessive cracking or spalling was not observed in the specimens using FNS aggregate in spite of the reduced thermal conductivity of mortar. The cracks in both types of specimens were similar and are considered to have occurred due to the temperature differential, especially in the cooling stage.

\subsubsection{Change of mass by exposure to high temperature}

Mass of the samples was recorded before and after the elevated temperature exposure, and the percentages of mass change at different temperatures were calculated. The results are shown in Fig. 15. 


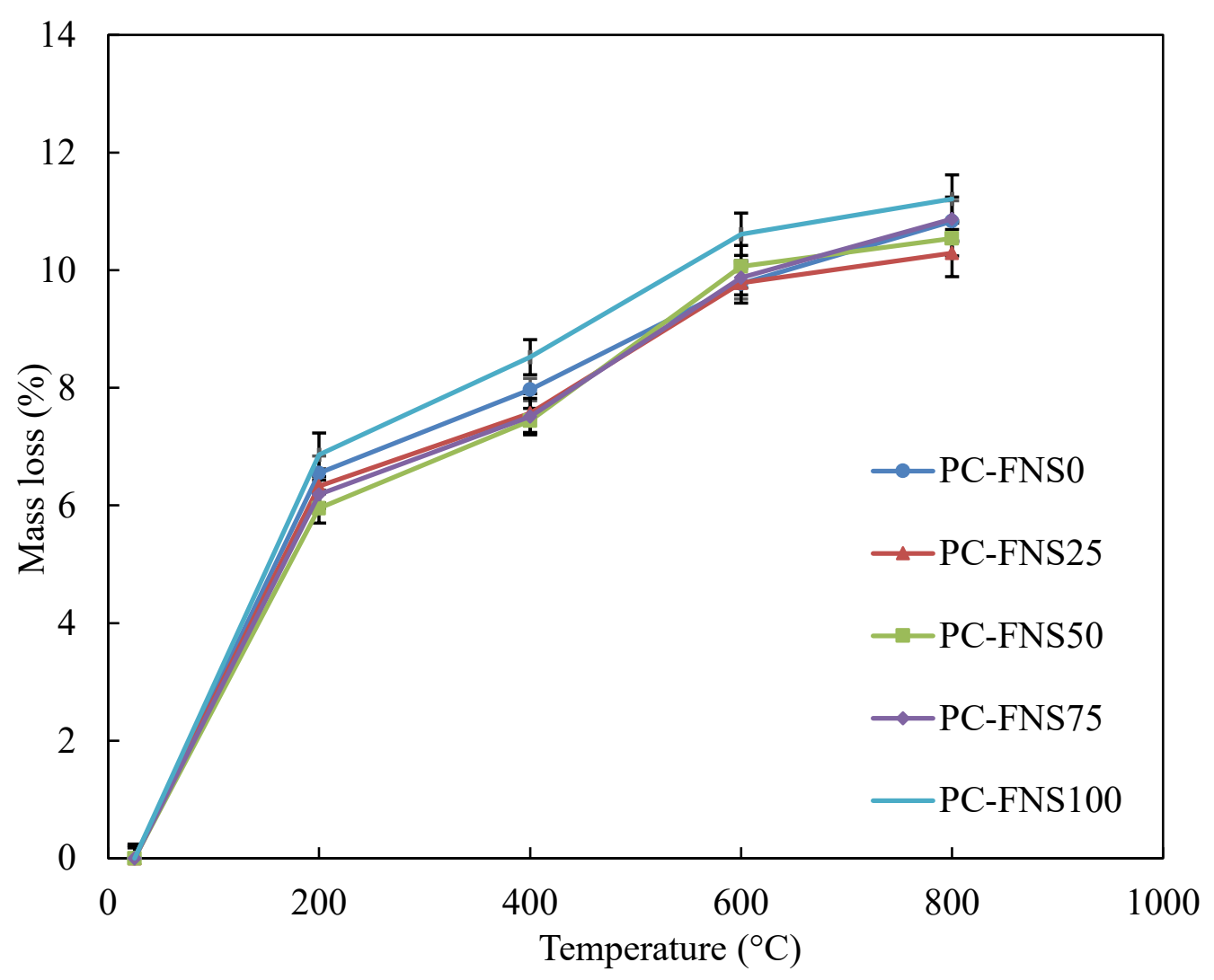

Fig. 15. Mass loss due to elevated temperature exposure.

It can be seen from Fig. 15 that the specimens exhibited a significant mass loss after exposure to $200{ }^{\circ} \mathrm{C}$. Afterwards, the mass loss increased at a slower rate for exposure to 400 ${ }^{\circ} \mathrm{C}$. Then, the mass loss again increased at a higher rate for exposure to $600{ }^{\circ} \mathrm{C}$. Finally, from $600{ }^{\circ} \mathrm{C}$ to $800{ }^{\circ} \mathrm{C}$, the mass loss increased at a declined rate. The reason for the substantial mass loss from room temperature to $200{ }^{\circ} \mathrm{C}$ is primarily due to the loss of physically bound water from the binder matrix. It is usually known that cement paste loses most of the physically bound water at temperatures up to $150{ }^{\circ} \mathrm{C}$ (Esteves, 2011). This corresponds to the significant mass loss observed in all the specimens up to $200{ }^{\circ} \mathrm{C}$. The mass loss between $400{ }^{\circ} \mathrm{C}$ and $600{ }^{\circ} \mathrm{C}$ was primarily associated with the decomposition of portlandite or $\mathrm{Ca}(\mathrm{OH})_{2}$ in the binder matrix. Decomposition of portlandite resulted in the escape of moisture from the samples and caused a notable mass loss. Besides, it can be seen that there was no noticeable variation of mass due to use of FNS aggregate as replacement of sand at different percentages. When the samples were exposed to $200{ }^{\circ} \mathrm{C}$, the mean mass variation was within a range of $5.95 \%$ to $6.86 \%$. Similar trend can be seen for all the temperatures, such as for $400{ }^{\circ} \mathrm{C}$, the variation was $7.44 \%$ to $8.52 \%$, for $600{ }^{\circ} \mathrm{C}$ the variation was $9.77 \%$ to $10.61 \%$ and for $800{ }^{\circ} \mathrm{C}$ the mass variation was within a range of $10.54 \%$ to $11.21 \%$. Fig. 10 also shows that, with the use of FNS aggregate, the mass loss fluctuated for $25 \%$ to $75 \%$ sand replacements. However, the mortar samples with $100 \%$ FNS aggregate (PC-FNS100) consistently exhibited a higher mass loss in all four temperature stages. This marginally higher mass loss of mortar with $100 \%$ FNS aggregate is considered to be associated with the higher moisture content of FNS aggregate. 
Compressive strength of the specimens was determined after the elevated temperature exposure and the percentage residual strength was calculated relative to the 28-day compressive strength of unheated samples. The residual strength percentages after exposure to different temperatures are shown in Fig. 16. It is noticeable that there was no strength loss of the control mortar (PCFNS0) after exposure to $200{ }^{\circ} \mathrm{C}$.

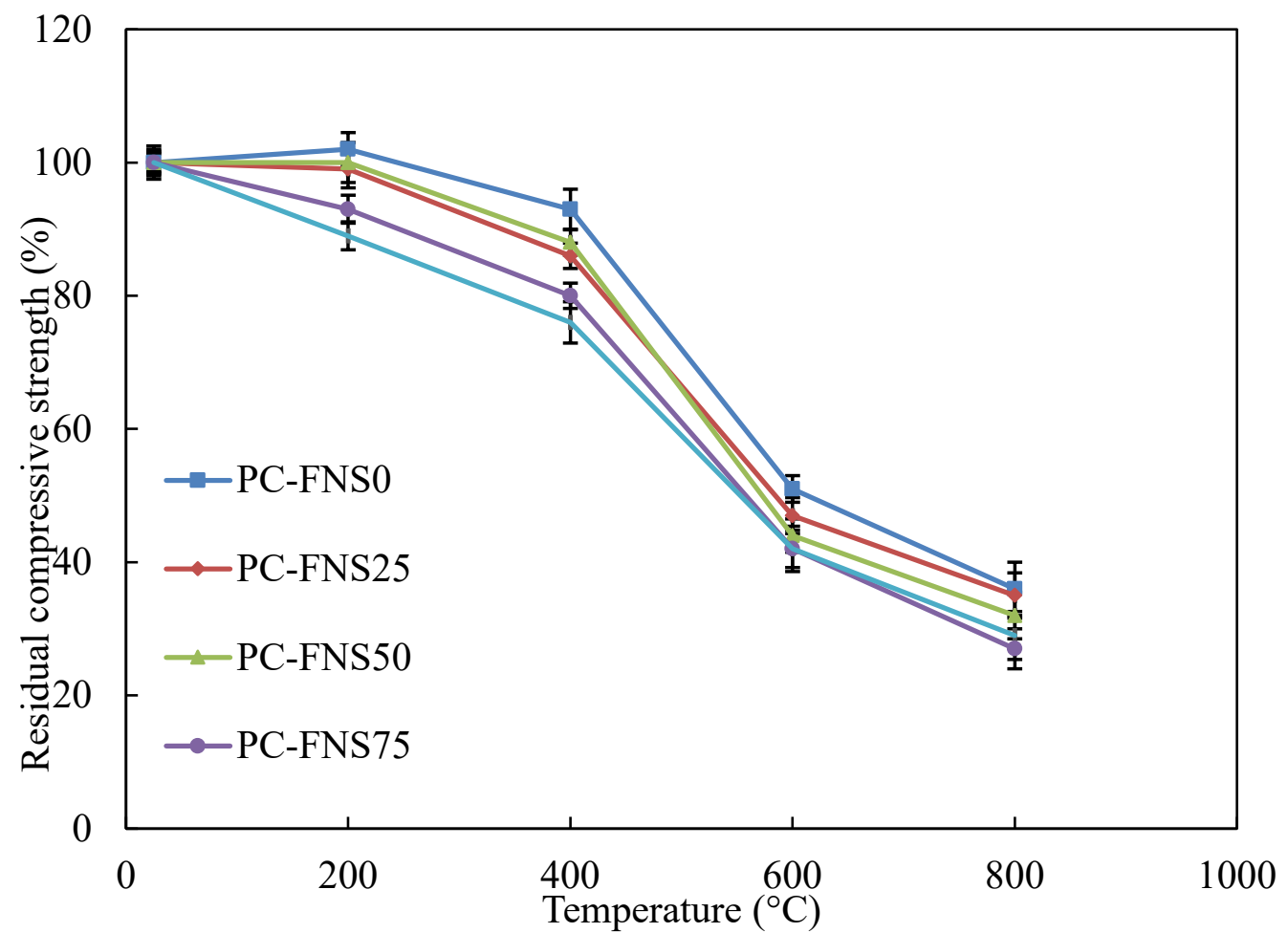

Fig. 16. Residual strength after exposure to different elevated temperatures.

However, replacement of sand by FNS aggregate gradually reduced the residual strength of mortar. Residual strengths of the specimens PC-FNS25, PC-FNS50, PC-FNS75 and PC-FNS100 were $99 \%, 100 \%, 93 \%$ and $89 \%$, respectively. Furthermore, there was a gradual reduction of compressive strength from 200 to $400{ }^{\circ} \mathrm{C}$ for all the five mortar specimens. The residual compressive strengths of specimens PC-FNS0, PC-FNS25, PC-FNS50, PC-FNS75 and PC-FNS100 were $93 \%, 86 \%, 88 \%, 80 \%$ and $76 \%$, respectively. With the increase of exposure temperature to $600{ }^{\circ} \mathrm{C}$, the specimens exhibited considerable strength loss with residual compressive strengths within a range of $42 \%$ to $51 \%$. The control mortar specimen, PC-FNS0 exhibited the highest residual strength and the samples with $100 \%$ FNS aggregates, PC-FNS100 exhibited the lowest residual strength. This noticeable reduction of residual strength at this temperature was primarily due to the decomposition of portlandite. The residual strength of the samples were $51 \%, 47 \%, 44 \%, 42 \%$ and $42 \%$ for PC-FNS0, PC-FNS25, PCFNS50, PC-FNS75 and PC-FNS100, respectively. Finally, after exposure to $800{ }^{\circ} \mathrm{C}$, the residual strengths of the samples were within a range of $27 \%$ to $36 \%$. Thus, the results indicate that the residual strength of mortar marginally declined with the increase of FNS aggregate. Previous studies on concrete with high-density aggregates exhibited significantly high strength loss and explosive spalling due to elevated temperature exposure (Ma et al., 2015). However, no spalling was observed in the mortar specimens containing FNS aggregate. This phenomenon 
is attributed to the higher VPV of the samples containing FNS aggregate that helped with the release of vapour pressure. Therefore, even though high density FNS aggregates were used in the mortar specimens exposed to elevated temperature, only marginal strength reduction was observed due to their higher porosity, low thermal conductivity and thermal diffusivity, which were observed in previous sections.

\section{Conclusions}

By-product ferronickel slag (FNS) was used in cement mortar as replacement of natural sand at different percentages. The effects of FNS on compressive strength, volume of permeable voids (VPV), thermal properties and residual strength after exposure to high temperature were studied. The following conclusions are drawn from the experimental results.

1. Compressive strength of mortar increased for using 25\% and 50\% FNS aggregates and then declined for $75 \%$ and $100 \%$ FNS aggregate. The change in strength by FNS is attributed to its effect on the mortar density and overall grading of fine aggregate.

2. Density of mortar increased by FNS aggregate due to its higher particle density. Also, porosity or VPV of mortar increased with the increase of FNS due to its large cavity and micropores, angular shape and larger size than sand.

3. Thermal conductivity and thermal diffusivity of mortar decreased with the increase of FNS content due to the increase of porosity. The decreases of thermal conductivity for using $50 \%$ and $100 \%$ FNS were $30 \%$ and $50 \%$, respectively. The increase of FNS content increased the heat capacity of mortar. Thus, the thermal insulating properties and thermal mass of mortar improved by use of FNS aggregate.

4. The residual strength of mortar after prolonged exposure to $600{ }^{\circ} \mathrm{C}$ decreased from $51 \%$ for using $0 \%$ FNS to $42 \%$ for $100 \%$ FNS. Similarly, the residual strengths decreased from $36 \%$ for $0 \%$ FNS to $27 \%$ for $100 \%$ FNS after exposure to $800{ }^{\circ} \mathrm{C}$. The marginally higher strength loss for using FNS aggregate is attributed to the decrease of thermal conductivity and diffusivity.

5. Overall, FNS aggregate improved the thermal insulating properties of cement mortar without sacrificing compressive strength. This can provide considerable benefits to the heating and cooling energy usage of buildings. Thus, FNS aggregate has the potential for practical applications in construction of energy efficient sustainable building products. Future trend would be investigation of the long term durability of mortar using FNS aggregate.

\section{Acknowledgements}

The authors would like to acknowledge the support of SLN, New Caledonia through its research department. Part of this research was undertaken using the EM instrumentation (ARC LE130100053) at the John de Laeter Centre, Curtin University.

\section{References}

Alengaram, U. J., Al Muhit, B. A., bin Jumaat, M. Z., \& Jing, M. L. Y. (2013). A comparison of the thermal conductivity of oil palm shell foamed concrete with conventional materials. Materials \& Design, 51, 522-529. 
Andrews-Phaedonos, F. (2008, July). Test methods for the assessment of durability of concrete. In ARRB conference, 23rd, 2008, Adelaide, South Australia, Australia.

AS 2701 (2001). Methods of sampling and testing mortar for masonry construction. Standards Australia, Sydney, Australia.

AS 2758.1 (2014). Aggregates and rock for engineering purposes Part 1: Concrete aggregates. Standards Australia, Sydney, Australia.

Ashworth, T., and Ashworth, E., in: Graves, R.S., and Wysocki, D.C. (Eds.). Insulation Materials: Testing and Applications. Vol. 1116, ASTM STP, Philadelphia, 1991, 415 429.

Berman, R. (1956). Some experiments on thermal contact at low temperatures. J. Applied Physics, 27(4), 318-323.

Bogas, J. A., de Brito, J., \& Figueiredo, J. M. (2015). Mechanical characterization of concrete produced with recycled lightweight expanded clay aggregate concrete. Journal of Cleaner Production, 89, 187-195.

Borinaga-Trevino, R., Pascual-Munoz, P., Castro-Fresno, D., \& Del Coz-Díaz, J. J. (2013). Study of different grouting materials used in vertical geothermal closed-loop heat exchangers. Applied Thermal Engineering, 50(1), 159-167.

Bouduerra, A., Laurent, J.P., Goual, M.S., and Queneudec, M. (1997). The measurement of the thermal conductivity of solid aggregates using the transient plane source technique. Journal of Physics D: Applied Physics, 30, 2900-2904.

Del Coz Díaz, J. J., Rabanal, F. P. Á., Nieto, P. J. G., Hernández, J. D., Soria, B. R., \& PérezBella, J. M. (2013). Hygrothermal properties of lightweight concrete: Experiments and numerical fitting study. Construction and Building Materials, 40, 543-555.

Del Coz Díaz, J. J., Nieto, P. G., Hernández, J. D., \& Rabanal, F. Á. (2010). A FEM comparative analysis of the thermal efficiency among floors made up of clay, concrete and lightweight concrete hollow blocks. Applied Thermal Engineering, 30(17-18), 2822-2826.

Demirboga, R., \& Kan, A. (2012). Thermal conductivity and shrinkage properties of modified waste polystyrene aggregate concretes. Construction and Building Materials, 35, 730734.

Emborg, M. (2014). Thermal stresses in concrete at early ages. In Analysis of concrete structures by fracture mechanics (pp. 74-89). CRC Press.

Esteves, L. P. (2011). On the hydration of water-entrained cement-silica systems: combined SEM, XRD and thermal analysis in cement pastes. Thermochimica Acta, 518(1-2), 2735.

Fu, X., \& Chung, D. D. L. (1997). Effects of silica fume, latex, methylcellulose, and carbon fibers on the thermal conductivity and specific heat of cement paste. Cement and concrete research, 27(12), 1799-1804. 
Gustafsson, S. E. (1991) Transient plane source techniques for thermal conductivity and thermal diffusivity measurements of solid materials. Review of Scientific Instruments, 62, 797. doi: 10.1063/1.1142087

Gustafsson, S. E., Karawaski, E., Chohan, M. A. (1986). Thermal transport studies of electrically conducting materials using the transient hot-strip technique. J. Phys. D: Applied Physics, 19, 727-735.

Güneyisi, E., Gesoglu, M., Ghanim, H., İpek, S., \& Taha, I. (2016). Influence of the artificial lightweight aggregate on fresh properties and compressive strength of the selfcompacting mortars. Construction and Building Materials, 116, 151-158.

Ghods, P., Alizadeh, R., Salehi, M. (2017). Electrical methods and systems for concrete testing, United States patent US 9, 638, 652. https://www.google.com/patents/ US9638652.

Institution of Structural Engineers, Concrete Society. (1987). Guide to the Structural Use of Lightweight Aggregate Concrete, I. Struct. E, London, 58p.

Kodur, V. (2014). Properties of concrete at elevated temperatures. ISRN Civil engineering, 2014.

Kodur, V. K. R., \& Sultan, M. A. (2003). Effect of temperature on thermal properties of highstrength concrete. Journal of materials in civil engineering, 15(2), 101-107.

Kodur, V. K. R., Cheng, F. P., Wang, T. C., \& Sultan, M. A. (2003). Effect of strength and fiber reinforcement on fire resistance of high-strength concrete columns. Journal of Structural Engineering, 129(2), 253-259.

Kong, D. L., \& Sanjayan, J. G. (2010). Effect of elevated temperatures on geopolymer paste, mortar and concrete. Cement and concrete research, 40(2), 334-339.

Kim, H. K., Jeon, J. H., \& Lee, H. K. (2012). Workability, and mechanical, acoustic and thermal properties of lightweight aggregate concrete with a high volume of entrained air. Construction and Building Materials, 29, 193-200.

Li, Z., Xu, J., \& Bai, E. (2012). Static and dynamic mechanical properties of concrete after high temperature exposure. Materials Science and Engineering: A, 544, 27-32.

Lightfoot, E.N., Bird, R.B., Stewart, W.E. (1960). Transport Phenomena. John Wiley and Sons, $780 \mathrm{p}$.

Liu, M. Y. J., Alengaram, U. J., Jumaat, M. Z., \& Mo, K. H. (2014). Evaluation of thermal conductivity, mechanical and transport properties of lightweight aggregate foamed geopolymer concrete. Energy and Buildings, 72, 238-245.

Mahlia, T. M. I., Taufiq, B. N., \& Masjuki, H. H. (2007). Correlation between thermal conductivity and the thickness of selected insulation materials for building wall. Energy and Buildings, 39(2), 182-187.

Ma, Q., Guo, R., Zhao, Z., Lin, Z., \& He, K. (2015). Mechanical properties of concrete at high temperature - a review. Construction and Building Materials, 93, 371-383.

Metha, K. P., \& Monteiro, P. J. M. (2006). Concrete Microstructure, Properties, and Materials (third ed.), McGraw-Hill, University of California at Berkeley 
Mirzazadeh, M. M., Noël, M., \& Green, M. F. (2016). Effects of low temperature on the static behaviour of reinforced concrete beams with temperature differentials. Construction and Building Materials, 112, 191-201.

Morabito, P. (1989). Measurement of the thermal properties of different concretes. High Temperatures. High Pressures, 21(1), 51-59.

Örüng, I. (1996). A research on usage possibilities of ground lightweight aggregate in agricultural buildings. Atatürk üniversitesi Ziraat fakultesi Dergisi, Turkey, 26(1).

Padmalal, D., Maya, K., Sreebha, S., \& Sreeja, R. (2008). Environmental effects of river sand mining: a case from the river catchments of Vembanad lake, Southwest coast of India. Environmental geology, 54(4), 879-889.

Papayianni, I., \& Valliasis, T. (2005). Heat deformations of fly ash concrete. Cement and Concrete Composites, 27(2), 249-254.

Pan, Z., Sanjayan, J. G., \& Kong, D. L. (2012). Effect of aggregate size on spalling of geopolymer and Portland cement concretes subjected to elevated temperatures. Construction and Building Materials, 36, 365-372.

Preciso, E., Salemi, E., \& Billi, P. (2012). Land use changes, torrent control works and sediment mining: effects on channel morphology and sediment flux, case study of the Reno River (Northern Italy). Hydrological Processes, 26(8), 1134-1148.

Ramírez, F. M. D., Muñoz, F. B., López, E. L., \& Polanco, A. V. (2013). Thermal evaluation of structural concretes for construction of biodigesters. Energy and Buildings, 58, 310318.

Resnick, R. and Halliday, D. (1966) Physics. John Wiley and Sons, 1334p.

Saha, A. K., \& Sarker, P. K. (2017a). Sustainable use of ferronickel slag fine aggregate and fly ash in structural concrete: mechanical properties and leaching study. Journal of Cleaner Production, 162, 438-448.

Saha, A. K., \& Sarker, P. K. (2017b). Durability characteristics of concrete using ferronickel slag fine aggregate and fly ash. Magazine of Concrete Research, 1-10.

Saha, A. K., \& Sarker, P. K. (2017c). Compressive strength of mortar containing ferronickel slag as replacement of natural sand. Procedia engineering, 171, 689-694.

Saha, A. K., \& Sarker, P. K. (2018a). Durability of Mortar Incorporating Ferronickel Slag Aggregate and Supplementary Cementitious Materials Subjected to Wet-Dry Cycles. International Journal of Concrete Structures and Materials, 12(1), 29.

Saha, A. K., \& Sarker, P. K. (2018b). Potential ASR expansion mitigation of ferronickel slag aggregate by fly ash. Structural Concrete. DOI:10.1002/suco.201700273 (in press).

Saha, A. K. (2018). Effect of class F fly ash on the durability properties of concrete. Sustainable Environment Research, 28(1), 25-31.

Saha, A. K., Khan, M. N. N., \& Sarker, P. K. (2018). Value added utilization of by-product electric furnace ferronickel slag as construction materials: A review. Resources, Conservation and Recycling, 134, 10-24. 
Saha, A. K., \& Sarker, P. K. (2016). Expansion due to alkali-silica reaction of ferronickel slag fine aggregate in OPC and blended cement mortars. Construction and Building Materials, 123, 135-142.

Sayadi, A. A., Tapia, J. V., Neitzert, T. R., \& Clifton, G. C. (2016). Effects of expanded polystyrene (EPS) particles on fire resistance, thermal conductivity and compressive strength of foamed concrete. Construction and building materials, 112, 716-724.

Sengul, O., Azizi, S., Karaosmanoglu, F., \& Tasdemir, M. A. (2011). Effect of expanded perlite on the mechanical properties and thermal conductivity of lightweight concrete. Energy and Buildings, 43(2-3), 671-676.

Smili, B., Messaoud, A., Bouchelaghem, W., Abadlia, L., Fazel, N., Benmoussa, A., Kaban, I., Gasser, F., \& Gasser, J. G. (2018). Temperature dependence of the electrical resistivity and absolute thermoelectric power of amorphous metallic glass Ni33. 3Zr66. 7. Journal of Non-Crystalline Solids, 481, 352-360.

Shen, D., Jiang, J., Shen, J., Yao, P., \& Jiang, G. (2016). Influence of curing temperature on autogenous shrinkage and cracking resistance of high-performance concrete at an early age. Construction and Building Materials, 103, 67-76.

Soleimanzadeh, S., \& Mydin, M. O. (2012). Influence of high temperatures on flexural strength of foamed concrete containing fly ash and polypropylene fiber. International Journal of Engineering-Transactions B: Applications, 26(2), 117.

Steiger, R.V., and Hurd, M.K. (1978). Lightweight insulating concrete for floors and roof decks. Concrete Constructions, 23(7), 411-422.

Thomas, T. R., Probert, S. D. (1970). Thermal contact resistance: the directional effect and other problems. Int. J. of Heat and Mass Transfer, 13(5), 789-807.

United States Environmental Protection Agency (US EPA). (2009). Hazardous waste characteristics. Available at: www.epa.gov/sites/production/files/201601/documents/hw-char.pdf (Accessed on 15 May 2015).

Williamson, M., Majumdar, R. (1992). Effect of surface deformations on contact conductance. Journal of Heat Transfer, 114, 802-810.

Won, J. P., Kang, H. B., Lee, S. J., Lee, S. W., \& Kang, J. W. (2011). Thermal characteristics of high-strength polymer-cement composites with lightweight aggregates and polypropylene fiber. Construction and Building Materials, 25(10), 3810-3819.

Yüzer, N., Aköz, F., \& Öztürk, L. D. (2004). Compressive strength-color change relation in mortars at high temperature. Cement and Concrete Research, 34(10), 1803-1807.

Yun, T. S., Jeong, Y. J., Han, T. S., \& Youm, K. S. (2013). Evaluation of thermal conductivity for thermally insulated concretes. Energy and Buildings, 61, 125-132.

Zhang, B., Bicanic, N., Pearce, C. J., \& Balabanic, G. (2000). Residual fracture properties of normal-and high-strength concrete subject to elevated temperatures. Magazine of Concrete Research, 52(2), 123-136. 